\title{
Influence of Urban Road Characteristics on Traffic Noise
}

\author{
Xiaodong $\mathrm{LU}^{\mathrm{a}}$, Jian KANG ${ }^{\mathrm{b}}$, Peisheng $\mathrm{ZHU}^{\mathrm{a}}$, Jun CAl ${ }^{\mathrm{a}}$, Fei GUO ${ }^{\mathrm{a}}$, Yuan ZHANG ${ }^{\mathrm{c}}$ \\ aSchool of Architecture and Fine Art, Dalian University of Technology, Dalian, China, \\ ${ }^{b} U C L$ Institute for Environmental Design and Engineering, University College London (UCL), UK, \\ 'School of Architecture and Urban Planning, Shenyang Jianzhu University, Shenyang, China
}

\begin{abstract}
Urban road networks significantly influence traffic noise. However, existing studies have neglected the causal chain between road characteristics and traffic noise; thus, clarity on their influencing mechanisms is lacking. In this study, structural equation models were developed to explore the mediated effect of road characteristics on traffic noise through traffic flow using data from field measurement in Dalian City, China; paired comparisons of scenarios though microscopic and macroscopic traffic simulations were performed for further analysis. The results show that lane number influences traffic noise mainly in terms of the number of vehicles in a group (NVG). More lanes indicate increased traffic demand due to connected urban land, which increases the NVG and, in turn, increases noise intensity but decreases noise amplitude. The influence of road segment length (RSL) on traffic noise mainly depends on the suppression effect. A longer RSL allows for higher vehicle speeds, leading to increased noise intensity and reduced noise amplitude. This also indicates that traffic flows disperse more easily, decreasing the NVG and, in turn, reducing noise intensity and increasing noise amplitude. Road junctions (RJ), which are classified according to the presence or absence of traffic lights, have significant direct effects on both noise intensity and noise amplitude, which are both likely to increase as drivers accelerate or decelerate in the middle of the road segment. These findings provide a reference for local governments and urban planners when working to improve quality of life in urban areas.
\end{abstract}

Keywords: traffic noise; road characteristics; road network; traffic flow; mediated effect; structural equation modelling

2019 Transportation Research Part D: Transport and Environment

Date Received: 2 Mar 2017 Date Accepted: 26 Aug 2018

Available online: 1 Sep 2019. 


\section{Introduction}

Noise pollution has a detrimental impact on quality of life. It diminishes comfort levels, inhibits the ability to communicate, disturbs tranquillity, and can even cause psychological problems and cardio-cerebrovascular diseases (Halonen et al., 2015; Stansfeld et al., 2005; Van Kempen et al., 2012). Of all the environmental stressors that can affect lives, noise pollution is ranked second (EEA, 2014; Fritschi et al., 2011; Ouis, 2001). Traffic noise is the primary source of noise pollution (SCU, 2017). One-third of the roads in China's metropolitan areas exceed the national standard permissible limit of $70 \mathrm{~dB}(\mathrm{~A})(\mathrm{MEP}, 2018)$. The effects of noise pollution at night are even more extreme (MEP, 2017).

Numerous factors affect traffic noise, among which traffic flow is an important influencing factor. The road network determines the distribution of traffic flow in an urban space and affects driver behaviour (Williams et al., 2014; Wu et al., 2008), which further affects noise levels. Thus, municipal-scale urban road networks, as well as block-scale road characteristics, are the central focus of urban traffic noise management (D'Alessandro et al., 2014; Naish, 2010; Ruiz-Padillo et al., 2014).

A number of studies have made progress in terms of understanding the influence of urban road networks on traffic noise. Wang and Kang (2011) studied noise pollution patterns in Wuhan, China, and Manchester, U.K., and stated that road coverage is significantly related to traffic noise. They also found different trends in the two cities in terms of the correlations between urban morphological indices and noise levels. Salomons and Pont (2012) reported that the spatial distribution of traffic noise is a function of local vehicle kilometres, population density, and urban form, concluding that road network density correlates positively with traffic noise. Ryu et al. (2017) found a positive relationship between road area density and traffic noise through spatial correlation analysis of noise mapping. Their conclusions contradicted those of Salomons and Pont (2012) with respect to the impact that the floor space index on traffic noise. Tang and Wang (2007) and Sheng and Tang (2011) compared different arrangements of road networks in Macau, demonstrating that narrow roads, complex road networks, and high-density intersections can lead to higher noise pollution. Barrigón Morillas et al. (2005) and Rey Gozalo et al. (2013) reported that urban noise can be stratified according to road functionality as a communication path between different regions of a city and between adjacent cities. These studies concentrated on the municipal scale, achieving a deep understanding of road networks, which can provide useful guidance to improve traffic noise. However, certain findings still require further clarification.

Additionally, urban planning requires discussion related to road characteristics at the block scale to guide specific design strategies. Certain road characteristics that directly affect the rolling noise of a vehicle, such as road gradient and road pavement, have been 
incorporated into various noise prediction models, such as CoRTN, ASJ RTN, and RLS 90 (Garg and Maji, 2014). These road characteristics were not considered in this study as their relationship with traffic noise, as well as their mechanisms, are relatively well known.

Road characteristics that reflect road dimensions, such as road width and road segment length, are closely related to and can effectively predict traffic noise (Golmohammadi et al., 2009). Nevertheless, these ignored discussing with road junctions together, which have been shown to significantly affect traffic noise. Some studies have focused on the noise generated at road junctions and presented detailed findings on intersections (Estévez-Mauriz and Forssén, 2018; Gardziejczyk and Motylewicz, 2016; Li et al., 2017), while ignoring their impact on the noise of an entire road. Therefore, in this study, road characteristics were limited to road width, road segment length, and road junctions to better conform to urban planning needs.

Overall, most previous results only reflect the direct relationship between urban road networks, road characteristics, and traffic noise; however, few previous studies have systematically investigated the intrinsic mechanisms between them. It should also be noted that different vehicle combinations produce different traffic noise levels. Therefore, even on the same road, traffic noise varies depending on the vehicles being driven. Thus, to fully explore the relationship between road networks or roads and traffic noise and, hence, explain contradicting prior conclusions and obtain broader applicable findings, the role of traffic flow should be considered.

The aim of this study is to explore how road characteristics influence traffic noise through traffic flow and to provide a reference for urban planning. First, field measurements were conducted to obtain data in Dalian City, China, for three variables: road characteristics, traffic flow, and traffic noise. Multiple mediation analyses were then performed using structural equation modelling (SEM), with road characteristic data as independent variables, traffic noise data as dependent variables, and traffic flow data as the mediators. The direct effects (DEs) and total indirect effects (TIEs) of road characteristics on traffic noise, as well as specific indirect effects (SIEs), were evaluated. TIEs clarify to what extent road characteristics influence traffic noise through traffic flow, whereas SIEs clarify how road characteristics influence traffic noise through traffic flow. Pathways with a greater effect were further investigated through microscopic traffic and noise simulations.

\section{Methods}

\subsection{Definitions of vehicle groups}

For conventional measurements of traffic noise (ISO, 2017), it is important to continue the measurement over a sufficiently long period. However, in urban agglomerations, traffic 
rarely flows freely (lannone et al., 2013). Stop-start conditions imposed by traffic lights and intersections can cause pauses in traffic flow. Therefore, acquired traffic noise data do not have a clear corresponding relationship with real-time traffic flow (Muaz et al., 2017). This study uses vehicle groups as the research object to ensure that traffic noise data are mainly attributable to passing vehicles as vehicle grouping is very common, especially when the traffic volume is large (but not saturated).

Vehicle groups were identified by applying the following criteria: 1) the average number of vehicles per lane in the group is greater than one;2) the vehicles in a group are in 'car-following' status, meaning that the headway time is less than $5 \mathrm{~s}$ (Parker 1996; Puan et al., 2004); that is, the headway distance in the group did not exceed $40 \mathrm{~m}$ given an average speed of $30 \mathrm{~km} / \mathrm{h}$; and 3) the distance between vehicle groups is not less than $100 \mathrm{~m}$ to increase the attenuation of noise from adjacent groups.

\subsection{Road characteristics data acquisition}

As depicted in Fig. 1, three indicators were selected as road characteristic variables: lane number (LN), road segment length (RSL), and road junction (RJ). LN represents the road width based on the number of lanes, which is considered a more representative parameter than the actual width of the road. The RSL is the distance between two adjacent motor vehicle intersections. The RJ is classified according to the presence or absence of traffic lights in the direction of the vehicle's travel. Roundabouts, another type of road junction, are not discussed in this study owing to the difficulties in collecting a sufficient number of measured samples to meet the requirements of both one-way roads and those ending with a roundabout in Dalian, yielding unconvincing results.

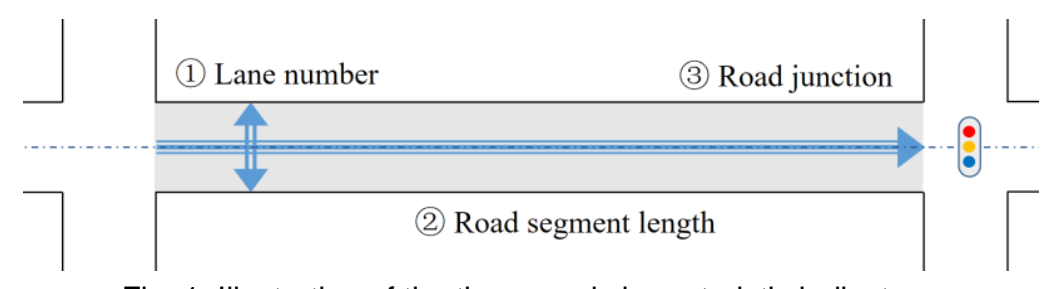

Fig. 1. Illustration of the three road characteristic indicators.

To clearly separate vehicle groups and reduce noise interference, only segments from one-way roads were included in the sample. This study selected samples in Dalian City, north-eastern China. Dalian's central road network was created during the colonial period under Russian and Japanese rule, with dense one-way roads that range from two to six lanes, which is rare in other Chinese cities. These features render Dalian particularly suitable for this study. In total, 20 typical one-way road segments were selected as samples. The roads have a gradient of $<3 \%$ and a lane width of approximately $3.5 \mathrm{~m}$. Conclusion biases due to the pavement type were excluded as the pavements of the road segment samples in this study were essentially the same, consisting of conventional medium grain 
asphalt concrete. The location distribution in Dalian is shown in Fig. 2; Table 1 presents an overview of the sampled road segments.

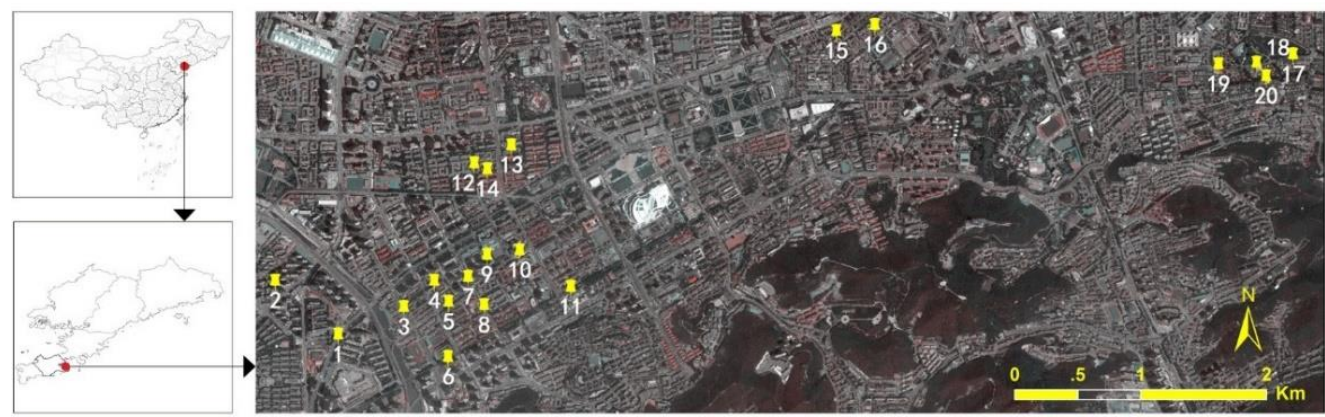

Fig. 2. Location distribution of sampled road segments in Dalian, China (source: Google Earth).

\subsection{Traffic noise and flow data acquisition}

Vehicle movement in the middle of a road segment is relatively stable, whereas at intersections, it is often altered by certain driving behaviours, such as acceleration, deceleration, and lane changing. Therefore, noise measurement points were set in the middle of the road segments to better reflect the influences of road characteristics on traffic noise, as shown in Fig. 3. Noise measurements commenced when the first car of the vehicle group arrived at the measurement point and ceased when the last car arrived at that point.

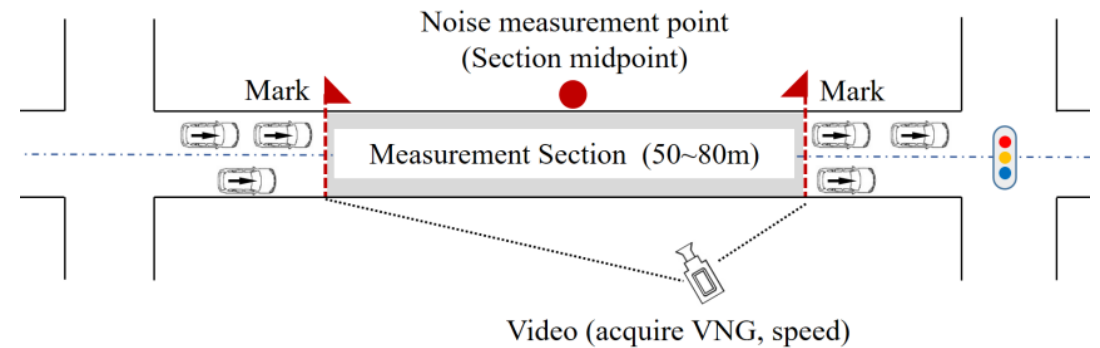

Fig. 3. Illustration of the measurement method.

Traffic noise is mainly measured in terms of two indicators: continuous equivalent $A$ weighted sound level, $L_{\text {Aeq, }}$ and statistical percentage sound level (i.e., $L_{10}$, $L_{50}$, and $L_{90}$ ). $L_{\text {Aeq }}$ is used to represent noise intensity as it has an improved correlation with the subjective perception of sound (Yang and Kang, 2005). The range from $L_{10}-L_{90}$ is used to represent noise amplitude, which is related to noise fluctuation (Can et al., 2008).

The following steps were taken to eliminate noise interference: 1) we ensured that noise from passing vehicles exceeded the background noise by at least $10 \mathrm{~dB}$ to avoid measuring other obvious noise sources, such as construction and crowd noise; 2) noise from other sudden sources, such as sirens or people, was excluded; and 3) noise from other vehicles, such as motorcycles and bicycles, was also excluded owing to its low occurrence frequency. 
Traffic flow variables consisted of three indicators. The first was the number of vehicles in a group (NVG), which reflects the traffic flow rate. This was used instead of traditional flow rate (vehicles per hour), which unsuitable when attempting to evaluate short-term changes in traffic flow. The second variable was the group speed $(\mathrm{km} / \mathrm{h})$. For each vehicle group, three to five typical vehicles were selected, each of which had a status of "carfollowing' with no lane changes. A segment speed was then obtained using video (Fig. 3), and the average group speed was calculated. The third variable was the heavy vehicle percentage (HVP); that is, the ratio of heavy vehicles (mainly buses and trucks) to total vehicles.

Table 1. Overview of sampled road segments.

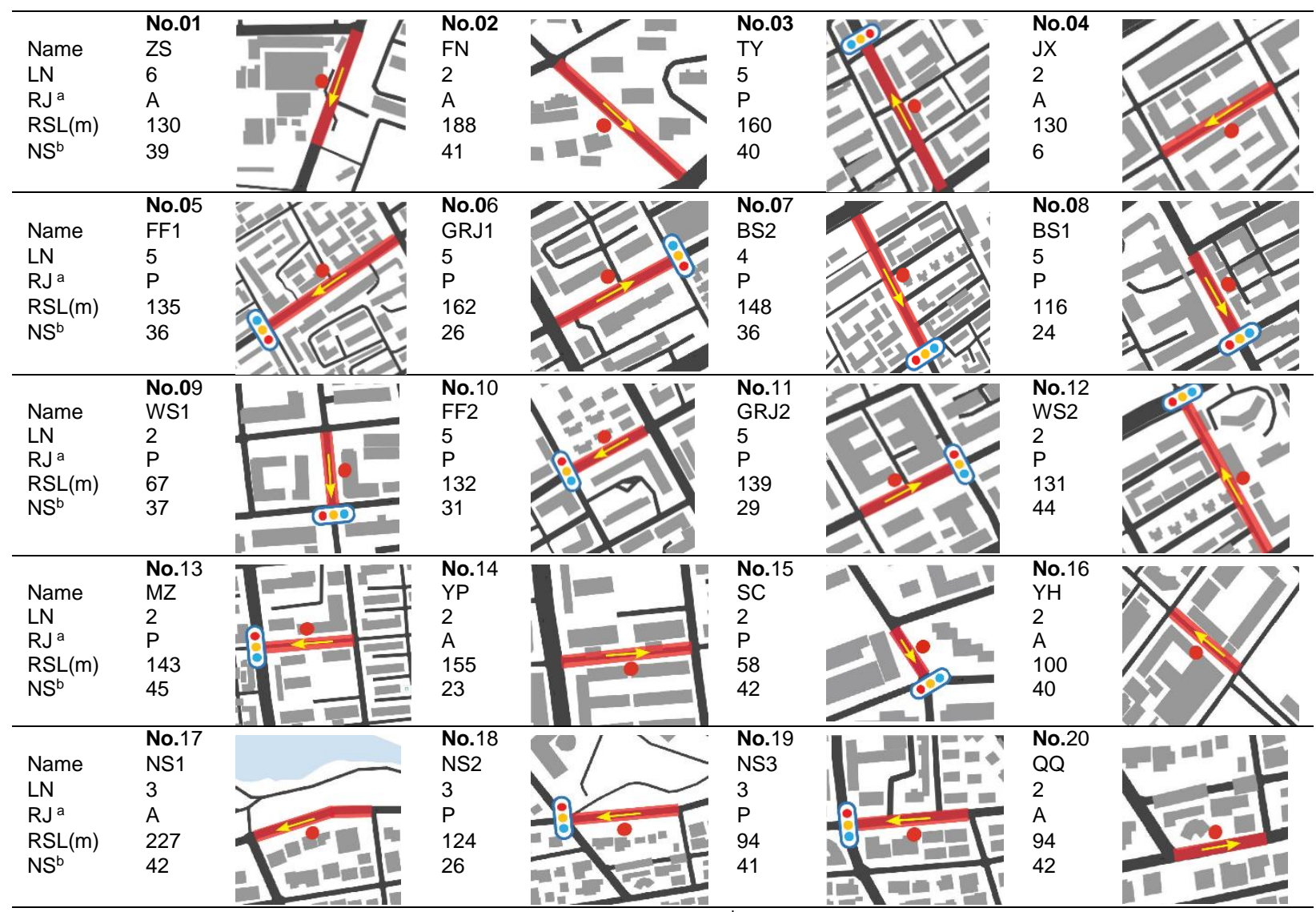

Note. aP: Traffic light presence; A: Traffic light absence; ${ }^{b} \mathrm{NS}$ : number of datasets obtained from each sampled road segment. Red areas identify selected road segments, which are consecutive vehicle roads, and are determined by two adjacent motor vehicle intersections; the red circle is the measurement position. Image sourced from Baidu Maps. LN, lane number; RJ, road junction; RSL, road segment length.

Noise was measured using a Class 1 B\&K 2250 sound level meter equipped with a wind protector. The meter was placed at a height of $1.5 \mathrm{~m}$, at a distance of $1.5 \mathrm{~m}$ from the road curb, and at least $5 \mathrm{~m}$ from the facades of buildings (Barrigón Morillas et al., 2016). Measurements were collected during non-peak traffic hours; that is, between 1 p.m. and 3 
p.m. on non-holidays. Weather conditions were cloudy, dry, and with a light breeze, with smooth traffic flow during the measurements. In total, 742 datasets were obtained; the number of datasets obtained for each sampled road segment are presented in Table 1. The average measurement time for each dataset was $38.8 \mathrm{~s}(\mathrm{SD}=30)$.

\subsection{Sample independence verification}

The Wald-Wolfowitz runs test (Bartels, 1982; Wald and Wolfowtiz, 1940) is a statistical test that determines whether the samples of a sequence are mutually independent and applies only to binomial variables. A run is a sequence of identical samples preceded and succeeded by different events or no event. In this study, the string of data obtained at the same measurement point was transformed into binomial data based on certain cut-off points obtained from its median. A string of data with too many or too few runs indicates that such data may not be random. As presented in Table A.1, the majority of the runs were insignificant, indicating that each dataset taken at the same point is independent.

This inference can also be explained empirically. The vehicle groups that passed in sequence were random and there was no mutual restriction between them. The measurements were also discontinuous because passing vehicles were often excluded as a result of not meeting the definition of vehicle grouping. This rendered the samples of traffic flow independent since there was no correlation among the passing vehicles while the corresponding traffic noise was also independent.

\subsection{Statistical analysis}

SEM is an extension of several multivariate techniques, including multiple regression analysis, pathway model analysis, and factor analysis. SEM is a more powerful alternative to regression analysis because simple regression models can only consider the direct effects that road characteristics have on traffic noise, and thus neglect the indirect effects (Fyhri and Klæboe, 2009; Hong and Jeon, 2015).

Compared with a simple mediation model, a multiple mediation model enables us to test multiple mechanisms from the antecedent to consequent variable (Hayes, 2013). Therefore, this study used the multiple mediation model via the PROCESS macro developed by Hayes (2013) and the IBM SPSS macros, which allow simultaneous testing of the DEs, TIEs, and SIEs. The TIE is the aggregate mediated effect of each SIE involved. Each SIE is associated with one of the road characteristic indicators, one of the traffic flow indicators, and one of the traffic noise indicators. The significance of each effect was tested using nonparametric bootstrapping, which is a computer-based resampling method that has higher statistical capabilities compared with the causal step and Sobel test methods (Hayes, 2009; Holbert and Stephenson, 2003). DEs, TIEs, and SIEs were calculated for 5,000 bootstrap samples as recommended by Preacher and Hayes (2008). Significant 
mediation is achieved if the $95 \%$ bias-corrected confidence intervals of the indirect effect parameters do not include zero. In addition, each dataset obtained at the same measurement point was directly applied in subsequent analyses since it was regarded as independent.

\subsection{Traffic and noise simulations}

There are two methods to analyse the results obtained from statistical analysis: (1) microscopic traffic and noise simulation, and (2) macroscopic traffic simulation.

The results can be validated through microscopic traffic and noise simulations based on vehicle driving behaviour. These simulations consist of three sequential parts: microscopic traffic simulation, vehicle noise emission simulation, and sound propagation simulation.

First, microscopic traffic simulation was performed to simulate traffic flow and obtain vehicle status data, including the position, speed, and acceleration of each vehicle at each simulation time step. In this study, Vissim vision 5.2 software was used. It is a time-based simulation in which driver-vehicle-units are modelled as single objects incorporating the Wiedemann 74 car-following model for urban traffic situations (Fellendorf, 2010). Then, status data of the vehicles were used in the vehicle noise emission model to calculate the noise emissions for each vehicle at a specific moment. The single vehicle noise emission model used in this study was obtained by regression analysis of measured data for Chinese roads ( $\mathrm{Li}$ et al., 2017). Finally, the vehicle position and noise emission were used in the sound propagation model to calculate the individual contribution of each vehicle at the receiver. Thus, the instantaneous sound pressure level at the receiver can be obtained by a summation of the contribution of each vehicle at the corresponding time-step. Distance and noise attenuation due to other factors were fully considered in the sound propagation model. Further details have been reported in Li et al. (2017) and the International Standard ISO 9613 (1996). The vehicle noise emission and sound propagation models were developed using a MATLAB procedure developed in this study.

Field measurements for model validation were conducted at Soft Park Road in Dalian, China. One receiving point was set at the middle of the road segment, as shown in Fig. 4. This point was selected in areas without buildings to reduce the influence of reflection. Traffic noise was measured for $20 \mathrm{~min}$ at the receiving point in terms of $L_{\text {Aeq, }} L_{10}, L_{50}$, and $L_{90}$. A simulated road was established based on the measured geometric dimension data, traffic volume data, and traffic control schemes at real intersections. The results show that simulated values of $L_{\text {Aeq }}, L_{10}, L_{50}$, and $L_{90}$ slightly differ from the measured values, with a maximum absolute error of $2.5 \mathrm{~dB}$, as shown in Table 2, which indicates that the accuracy of the model is acceptable. 


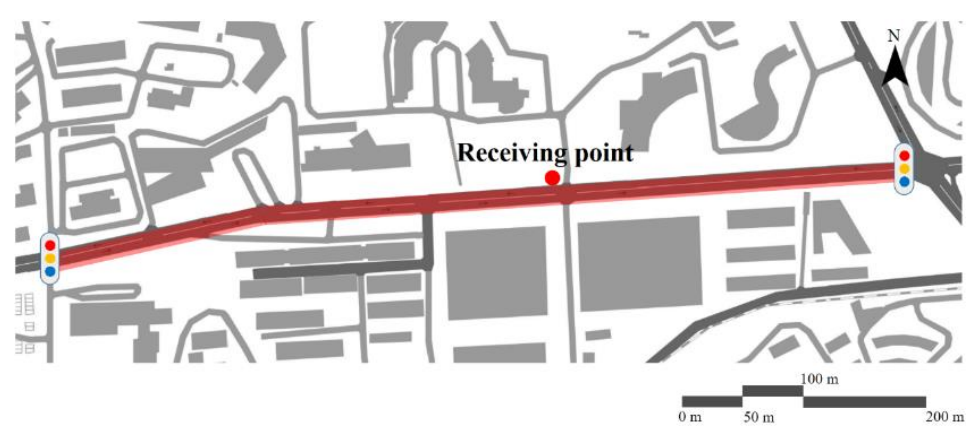

Fig. 4. Sampled road segments for model validation in Dalian, China (source: Baidu Maps).

Table 2. Comparison of simulated and measured $\mathrm{L}_{\mathrm{Aeq}}, \mathrm{L}_{10}, \mathrm{~L}_{50}$ and $\mathrm{L}_{90}$ parameters at the receiving point with a 20-min simulation period.

\begin{tabular}{lllll}
\hline & $\mathrm{L}_{\text {Aeq }}$ & $\mathrm{L}_{10}$ & $\mathrm{~L}_{50}$ & $\mathrm{~L}_{90}$ \\
\hline Measured data $(\mathrm{dB})$ & 70.5 & 73.2 & 68.1 & 61.9 \\
Average of four simulations $(\mathrm{dB})$ & 69.8 & 74.6 & 67.6 & 59.4 \\
Difference $(\mathrm{dB})$ & 0.7 & -1.4 & 0.5 & 2.5 \\
\hline
\end{tabular}

The results were also examined through macroscopic traffic simulation. Control delay was chosen as the indicator, which is a criterion for determining the level of service (LOS) at intersections designated by the American Highway Capacity Manual (HCM). It is caused by a control device (i.e., a traffic signal or a STOP-sign), including initial deceleration delay, queue move-up time, stopped delay, and final acceleration delay. The Highway Capacity Software (HCS) vision 7.8 was used to calculate control delays. This software was developed and is maintained by McTrans as a faithful implementation of HCM procedures. This version includes updated modules to implement HCM 6th Edition (TRB, 2016) procedures.

\section{Results}

Multiple mediation analyses of the 742 datasets were performed using SEM to clarify: 1) the extent to which the road characteristics influence traffic noise and its dependence on changes in traffic flow, 2) the extent to which the effect of each specific pathway is included in the causal chain between road characteristics and traffic noise, and 3) the effect to which differences in road characteristics influence noise intensity and amplitude.

\subsection{Correlation analysis}

Table 3 lists the means, standard deviations, and correlation matrices for the study variables. The RJ was set depending on the presence of a traffic light at the intersection, i.e., 1 if present and 2 if absent. According to Cohen (1988), there are two pairs of indicators 
with strong correlation $(|r|>0.5)$, four pairs with moderate correlation $(0.3<|r|<0.5), 17$ pairs with weak correlation $(|r|<0.3)$, and five pairs with insignificant correlation.

Table 3. Means, standard deviations, and correlation matrices for all variables $(\mathrm{N}=742)$.

\begin{tabular}{|c|c|c|c|c|c|c|c|c|c|c|}
\hline & \multirow[t]{2}{*}{ Mean } & \multirow[t]{2}{*}{ SD } & \multicolumn{8}{|c|}{ Pearson's r correlations } \\
\hline & & & 1 & 2 & 3 & 4 & 5 & 6 & 7 & 8 \\
\hline 1. LN & 3.38 & 1.43 & 1 & & & & & & & \\
\hline 2. $\mathrm{RSL}^{\mathrm{a}}$ & 131.4 & 40.4 & $.260^{* *}$ & 1 & & & & & & \\
\hline 3. $R J^{b}$ & 1.31 & 0.46 & $-.252^{* *}$ & $.286^{* *}$ & 1 & & & & & \\
\hline 4. NVG & 27.80 & 34.98 & $.737^{* *}$ & $.148^{* *}$ & $-.101^{* *}$ & 1 & & & & \\
\hline 5. Speed ${ }^{c}$ & 33.58 & 9.32 & $.098^{* *}$ & $.331^{\star *}$ & $.251^{* \star}$ & - & 1 & & & \\
\hline 6. HVP & 0.06 & 0.09 & $.176^{* *}$ & - & - & $.138^{* *}$ & $.081^{*}$ & 1 & & \\
\hline 7. LAeq & 72.05 & 3.37 & $.489^{* *}$ & $.221^{* *}$ & - & $.554^{* *}$ & $.439^{* *}$ & $.297^{* *}$ & 1 & \\
\hline 8. $L_{10}-L_{90}$ & 9.05 & 3.15 & $-.291^{* *}$ & $-.230^{* *}$ & $-.179^{* *}$ & $-.327^{* *}$ & $-.162^{* *}$ & - & $-.215^{* *}$ & 1 \\
\hline
\end{tabular}

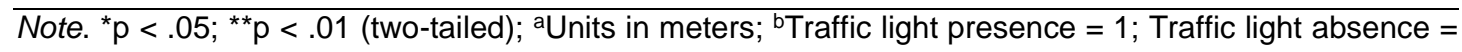
2; ' Units in $\mathrm{km} / \mathrm{h}$.

\subsection{Structural equation model}

Preliminary structural models were established using road characteristic data (LN, $R S L$, and $R J$ ) as the independent variables, traffic noise data ( $L_{\text {Aeq }}$ and $\left.L_{10}-L_{90}\right)$ as the dependent variables, and traffic flow data (NVG and group speed) as the mediator variables. $L_{\text {Aeq }}$ was the dependent variable in Model $A$ while $L_{10}-L_{90}$ was the dependent variable in Model B, as shown in Fig. 5(a) and 4(b), respectively. HVP was introduced as an independent variable to closely match real scenarios; however, no special analysis was performed. The recommended values of the fit indices were selected according to the guideline reported in Hu and Bentler (1999) and Jackson et al. (2003). Models A and B meet the recommended values for the comparative fit index (CFI), incremental fit index (IFI), Tucker-Lewis index (TLI), goodness-of-fit index (GFI), and adjusted goodness-of-fit index (AGFI), as presented in Table 4. However, models $A$ and $B$ do not meet the recommended values for the chi square to $\mathrm{df}$ ratio $\left(\mathrm{X}^{2} / \mathrm{df} ; 6.231>2.0\right)$ and root-meansquare error of approximation (RMSEA; $0.084>0.05)$. This shows that the models have certain defects.

Table 4. Goodness-of-fit of structural equation modelling (SEM). N = 742.

\begin{tabular}{|c|c|c|c|c|c|c|c|c|}
\hline \multicolumn{2}{|c|}{ Fit indices } & $\mathrm{X}^{2} / \mathrm{df}$ & RMSEA & $\mathrm{CFI}$ & $\mathrm{IFI}$ & TLI & GFI & AGFI \\
\hline \multicolumn{2}{|c|}{ Recommended value } & $<2.00$ & $<0.05$ & $>0.90$ & $>0.90$ & $>0.90$ & $>0.90$ & $>0.90$ \\
\hline \multirow[t]{4}{*}{ Model } & A & 6.231 & 0.084 & 0.990 & 0.990 & 0.929 & 0.993 & 0.934 \\
\hline & $\mathrm{B}$ & 6.231 & 0.084 & 0.986 & 0.979 & 0.901 & 0.999 & 0.934 \\
\hline & $\mathrm{C}$ & 1.698 & 0.031 & 0.999 & 0.999 & 0.990 & 0.999 & 0.982 \\
\hline & $\mathrm{D}$ & 1.698 & 0.031 & 0.999 & 0.999 & 0.987 & 0.999 & 0.982 \\
\hline
\end{tabular}

Note. $\mathrm{X}^{2} / \mathrm{df}$ : chi square to df ratio; RMSEA: root-mean-square error of approximation; CFI: comparative fit index; IFI: incremental fit index; TLI: Tucker-Lewis index; GFI: goodness-of-fit index; AGFI: adjusted goodness-of-fit index. 
In real scenarios, the NVG may be negatively related to group speed. Therefore, the NVG and group speed were combined to optimise the multiple mediation models, which yielded models $C$ and $D$, as shown in Fig. $5(\mathrm{c})$ and $4(\mathrm{~d})$, respectively. $L_{\text {Aeq }}$ is the dependent variable in model $C$, whereas $L_{10}-L_{90}$ is the dependent variable in model $D$. Table 3 indicates that the fit indices of models $C$ and $D$ were characterised by significant improvement, such that the results for the $X^{2} / d f$ and RMSEA tests now meet the recommended values, as well as the fact that the other indices improved by varying degrees. Overall, the fit between the theoretical model and measured data is relatively good. Subsequent analysis was performed using models $C$ and D. Interestingly, although the correlation between the group speed and NVG was not strong $(r=0.081, p<0.05$, see Table 2), the connection between them plays an important role in improving the fitness index. It should be noted that $L_{\text {Aeq }}$ represents various indicators of noise intensity, considering the strong correlation between $L_{\text {Aeq }}$ and $L_{10}, L_{50}$, and $L_{90}(r=0.952,0.910$, 0.807 , respectively). This can also be confirmed as follows: if $L_{10}, L_{50}$, and $L_{90}$ replace $L_{\text {Aeq }}$ as the dependent variable in model C (as presented in Table A.2 and Fig. A.1), the fit index values, pathway coefficient, and $R^{2}$ of the obtained SEM essentially remain the same.

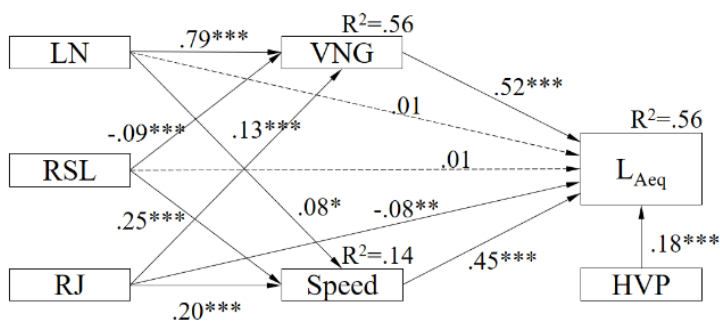

a) Model $A$

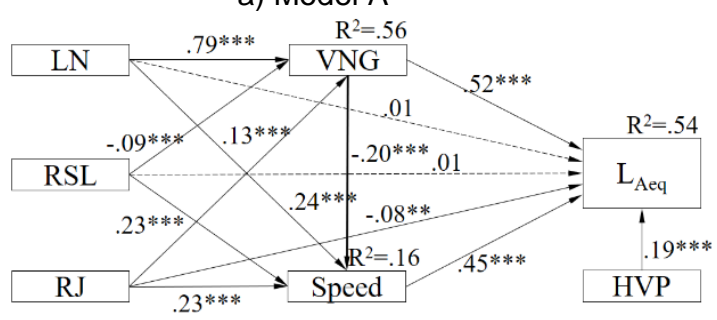

c) Model C

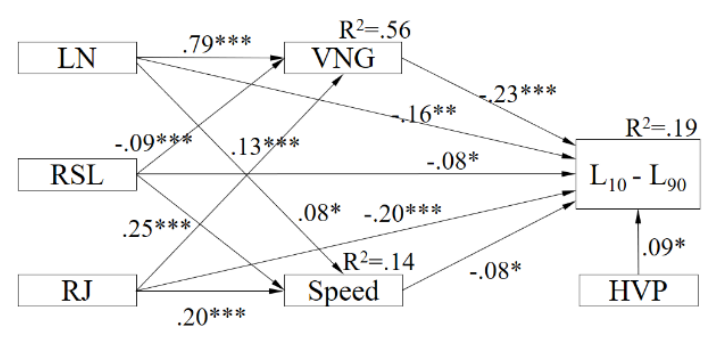

b) Model B

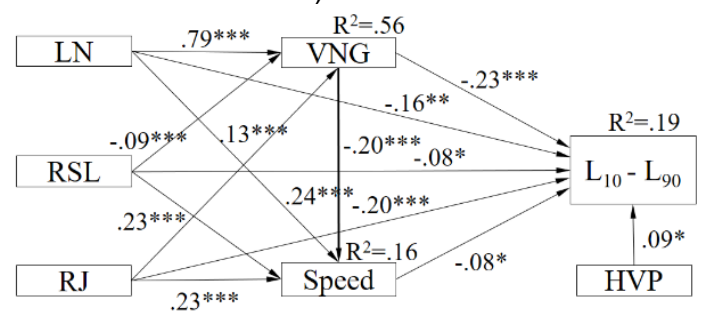

d) Model D

Fig. 5. Structural equation models. (a) Model A: preliminary model with LAeq as the dependent variable; (b) Model B: preliminary model with $\mathrm{L}_{10}-\mathrm{L}_{90}$ as the dependent variables; (c) Model C: optimised model with LAeq as the dependent variable; (d) Model D: optimised model with $\mathrm{L}_{10}-\mathrm{L}_{90}$ as the dependent variables. Notes. LN, lane number; RJ, road junction; RSL, road segment length; HVP, heavy vehicles percentage; NVG, number of vehicles in a group. Numbers in the figure represent standardised regression coefficients derived from the bootstrapping procedure. Solid lines represent the significant indirect pathways $\left({ }^{*} p<0.05\right.$, $\left.{ }^{* *} p<0.01,{ }^{* * *} p<0.001\right)$

There are three chained mediated pathways for the SIE of each road characteristic indicator on the noise indicator. Taking LN as an example: 1) SIE1: LN $\rightarrow$ NVG $\rightarrow L_{\text {Aeq, }}$ 2) 
SIE2: $\mathrm{LN} \rightarrow$ Speed $\rightarrow \mathrm{L}_{\text {Aeq }}$, and 3) SIE3: $\mathrm{LN} \rightarrow \mathrm{NVG} \rightarrow$ Speed $\rightarrow \mathrm{L}_{\text {Aeq. }}$. According to Preacher and Hayes (2008), SIEs should be examined even when the total effect (TE) is not significant since suppression effects may obscure the SIEs. In this study, all DEs, TIEs, and SIEs were calculated and compared.

\subsection{Effect of lane number on noise}

Table 5 lists the parameter estimates and confidence intervals of the effect of $L N$ on $L_{\text {Aeq. }}$. The TE of $L N$ on noise intensity is positive and significant; when $L N$ increases by 1 , $L_{\text {Aeq }}$ increases by $1.073 \mathrm{~dB}(\mathrm{BC} 95 \% \mathrm{Cl}[0.920,1.234])$. It should be noted that the $\mathrm{DE}$ represents the influence that $\mathrm{LNs}$ have on noise with respect to the assumption that there are no changes in the NVG and speed. The DE is not significant, which indicates that simple changes in physical space have a minimal effect on noise intensity.

Table 5. Unstandardized direct effect (DE), total indirect effect (TIE), total effect (TE), and specific indirect effect (SIE) of lane number (LN) on LAeq.

\begin{tabular}{|c|c|c|c|c|c|c|c|c|c|}
\hline \multirow[t]{2}{*}{$\mathrm{LN} \rightarrow \mathrm{L}_{\text {Aeq }}$} & \multirow[t]{2}{*}{$\begin{array}{l}\text { Point } \\
\text { Estimate }\end{array}$} & \multicolumn{2}{|c|}{$\begin{array}{l}\text { Product of } \\
\text { coefficients }\end{array}$} & \multicolumn{6}{|c|}{$\begin{array}{l}\text { Bootstrap 5,000 times } 95 \% \mathrm{Cl} \\
\text { Bias corrected }\end{array}$} \\
\hline & & SE & Z & Lower & Upper & $p$ & Lower & Upper & $\mathrm{p}$ \\
\hline \multicolumn{10}{|l|}{ DE \& IE \& TE } \\
\hline DE & .025 & .111 & .225 & -.185 & .249 & .791 & -.196 & .236 & .852 \\
\hline TIE & 1.047 & .076 & 13.776 & .907 & 1.201 & .000 & .906 & 1.200 & .000 \\
\hline TE & 1.073 & .080 & 13.413 & .920 & 1.234 & .000 & .914 & 1.227 & .000 \\
\hline TIE vs. DE & 1.022 & .173 & 5.908 & .686 & 1.357 & .000 & .697 & 1.363 & .000 \\
\hline \multicolumn{10}{|l|}{ SIE } \\
\hline $\mathrm{S1} . \mathrm{LN} \rightarrow \mathrm{NVG} \rightarrow \mathrm{L}_{\text {Aeq }}$ & .961 & .065 & 14.785 & .842 & 1.094 & .000 & .840 & 1.093 & .000 \\
\hline S2. $\mathrm{LN} \rightarrow$ Speed $\rightarrow \mathrm{L}_{\text {Aeq }}$ & .251 & .061 & 4.115 & .139 & .379 & .000 & .140 & .380 & .000 \\
\hline $\begin{array}{l}\text { S3. LN } \rightarrow \text { NVG } \rightarrow \text { Speed } \rightarrow \\
\text { L Aeq } \\
\text { Contrast between SIEs }\end{array}$ & -.165 & .047 & -3.511 & -.266 & -.080 & .000 & -.264 & -.079 & .000 \\
\hline S1 vs.S2 & .709 & .083 & 8.542 & .553 & .880 & .000 & .547 & .872 & .000 \\
\hline S1 vs. S3 & 1.126 & .090 & 12.511 & .963 & 1.319 & .000 & .957 & 1.310 & .000 \\
\hline S2 vs. S3 & .416 & .098 & 4.245 & .236 & .623 & .000 & .234 & .620 & .000 \\
\hline
\end{tabular}

Note. DE: direct effect; TIE: total indirect effect; TE: total effect; SIE: specific indirect effect; LN: lane number; NVG: number of vehicles in a group.

Within the TIE, three SIEs are significant with significant differences between them. The greatest effect among these is the pathway via the NVG: when LN increases by 1 , the NVG increases by 19.33 vehicles (BC 95\% Cl [17.79, 20.91]), and $L_{\text {Aeq }}$ also increases by $0.961 \mathrm{~dB}(\mathrm{BC} 95 \% \mathrm{Cl}[.842,1.094])$. This is probably because more lanes indicate greater traffic demand generated by connected urban land, with the resultant higher traffic volume raising the level of traffic noise. The second greatest effect is the pathway via speed: each additional lane increases the group speed by $1.56 \mathrm{~km} / \mathrm{h}$ (BC 95\% $\mathrm{Cl}[0.890,2.247])$, and $L_{\text {Aeq }}$ also increases by $0.251 \mathrm{~dB}$ (BC 95\% $\left.\mathrm{Cl}[0.139,0.379]\right)$. The weakest effect is the pathway via the NVG and group speed, which is significantly less than the other two pathways, and was mainly used to improve the fitness index. In addition, effects from the 
remaining pathways via the NVG and group speed are significant but weak; therefore, none of them are analysed below.

Table 6 lists the parameter estimates and confidence intervals of the effect of LN on $L_{10}-L_{90}$. The TE of the $L N$ on noise amplitude is negative and significant. For each additional lane, $\mathrm{L}_{10}-\mathrm{L}_{90}$ decreases by $0.764 \mathrm{~dB}$ (BC 95\% Cl [-0.909, -0.620$\left.]\right)$. Both the DE and TIE are also negative and significant, but the difference between them is not. In terms of $D E$, this is because a greater number of lanes leads to less chaotic driving behaviour and vehicles travel more smoothly; thus, noise amplitude is smaller.

Within the TIE, three SIEs are significant. The greatest effect is the pathway via the NVG: each additional lane increases the NVG by 19.33 vehicles (BC 95\% Cl [17.79, $20.91])$, thereby reducing $L_{10}-L_{90}$ by $0.404 \mathrm{~dB}(\mathrm{BC} 95 \% \mathrm{Cl}[-0.557,-0.262])$. The second greatest effect is the pathway via speed: each additional lane increases the group speed by $1.56 \mathrm{~km} / \mathrm{h}(\mathrm{BC} 95 \% \mathrm{Cl}[.890,2.247])$, thereby reducing $\mathrm{L}_{10}-\mathrm{L}_{90}$ by $0.043 \mathrm{~dB}$ (BC $95 \%$ $\mathrm{Cl}[-.095,-.007])$.

Table 6. Unstandardized direct effect (DE), total indirect effect (TIE), total effect (TE), and specific indirect effect (SIE) of lane number (LN) on L ${ }_{10}-\mathrm{L}_{90}$.

\begin{tabular}{|c|c|c|c|c|c|c|c|c|c|}
\hline \multirow{3}{*}{$\mathrm{LN} \rightarrow \mathrm{L}_{10}-\mathrm{L}_{90}$} & \multirow{3}{*}{$\begin{array}{l}\text { Point } \\
\text { Estimate }\end{array}$} & \multirow{2}{*}{\multicolumn{2}{|c|}{$\begin{array}{l}\text { Product of } \\
\text { coefficients }\end{array}$}} & \multicolumn{6}{|c|}{ Bootstrap 5,000 times $95 \% \mathrm{Cl}$} \\
\hline & & & & \multicolumn{3}{|c|}{ Bias corrected } & \multicolumn{3}{|c|}{ Percentile } \\
\hline & & SE & Z & Lower & Upper & $p$ & Lower & Upper & $p$ \\
\hline \multicolumn{10}{|l|}{ DE \& TIE \& TE } \\
\hline DE & -.346 & .112 & -3.089 & -.556 & -.122 & .002 & -.560 & -.127 & .002 \\
\hline TIE & -.418 & .076 & -5.500 & -.575 & -.276 & .000 & -.572 & -.272 & .000 \\
\hline TE & -.764 & .074 & -10.324 & -.909 & -.620 & .000 & -.905 & -.618 & .000 \\
\hline TIE vs. DE & -.073 & .177 & -.412 & -.432 & .262 & .681 & -.427 & .266 & .696 \\
\hline \multicolumn{10}{|l|}{ SIE } \\
\hline $\mathrm{S} 1 . \mathrm{LN} \rightarrow \mathrm{NVG} \rightarrow \mathrm{L}_{10}-\mathrm{L}_{90}$ & -.404 & .075 & -5.387 & -.557 & -.262 & .000 & -.554 & -.257 & .000 \\
\hline S2. $\mathrm{LN} \rightarrow$ Speed $\rightarrow \mathrm{L}_{10}-\mathrm{L}_{90}$ & -.043 & .022 & -1.955 & -.095 & -.007 & .019 & -.091 & -.004 & .028 \\
\hline S3. LN $\rightarrow$ NVG $\rightarrow$ Speed $\rightarrow \mathrm{L}_{10}-\mathrm{L}_{90}$ & .028 & .015 & 1.867 & .006 & .066 & .015 & .003 & .061 & .028 \\
\hline \multicolumn{10}{|l|}{ Contrast between SIE } \\
\hline S1 vs.S2 & -.361 & .077 & -4.688 & -.522 & -.217 & .000 & -.515 & -.213 & .000 \\
\hline S1 vs. S3 & -.432 & .077 & -5.610 & -.597 & -.289 & .000 & -.588 & -.283 & .000 \\
\hline S2 vs. S3 & -.071 & .035 & -2.029 & -.155 & -.013 & .019 & -.149 & -.007 & .028 \\
\hline
\end{tabular}

\subsection{Effect of road segment length on noise}

Table 7 lists the parameter estimates and confidence intervals for the effect of RSL on $L_{\text {Aeq. }}$ The TE of road length on noise intensity is positive and significant: each additional 10 $\mathrm{m}$ of road segment increases $L_{\text {Aeq }}$ by $0.060 \mathrm{~dB}(\mathrm{BC} 95 \% \mathrm{Cl}[0.010,0.110])$. The influence of RSL on traffic noise mainly depends on traffic flow changes since DE is not significant.

Within the TIE, three SIEs are significant, and the two main effects are in opposite directions. The greatest effect is the pathway via speed: each additional $10 \mathrm{~m}$ increases the group speed by $0.54 \mathrm{~km} / \mathrm{h}(\mathrm{BC} 95 \% \mathrm{Cl}[0.355,0.722])$, thereby increasing the $L_{\text {Aeq }}$ by $0.087 \mathrm{~dB}(\mathrm{BC} 95 \% \mathrm{Cl}[0.058,0.117])$. The second greatest effect is the pathway via the 
NVG: for each additional $10 \mathrm{~m}$, the NVG is reduced by 0.81 vehicles $(\mathrm{BC} 95 \% \mathrm{Cl}[-1.118$, $-0.505])$, thereby reducing the $L_{\text {Aeq }}$ by $0.040 \mathrm{~dB}(\mathrm{BC} 95 \% \mathrm{Cl}[-0.056,-0.026])$. This is probably because longer roads allow easier dispersions in the traffic flow. Thus, for the same average speed, fewer vehicles in a group generate less noise.

Table 7. Unstandardized direct effect (DE), total indirect effect (TIE), total effect (TE), and specific indirect effect (SIE) of road segment length (RSL) on LAeq.

\begin{tabular}{|c|c|c|c|c|c|c|c|c|c|}
\hline \multirow{3}{*}{$\mathrm{RSL} \rightarrow \mathrm{L}_{\text {Aeq }}$} & \multirow{3}{*}{$\begin{array}{l}\text { Point } \\
\text { Estimate }\end{array}$} & \multirow{2}{*}{\multicolumn{2}{|c|}{$\begin{array}{l}\text { Product of } \\
\text { coefficients }\end{array}$}} & \multicolumn{6}{|c|}{ Bootstrap 5,000 times $95 \% \mathrm{Cl}$} \\
\hline & & & & \multicolumn{3}{|c|}{ Bias corrected } & \multicolumn{3}{|c|}{ Percentile } \\
\hline & & SE & Z & Lower & Upper & $\mathrm{p}$ & Lower & Upper & $\mathrm{p}$ \\
\hline \multicolumn{10}{|l|}{ DE \& TIE \& TE } \\
\hline DE & .0006 & .023 & .261 & -.0039 & .0054 & .753 & -.0039 & .0053 & .786 \\
\hline TIE & .0053 & .014 & 3.786 & .0025 & .0081 & .000 & .0025 & .0081 & .000 \\
\hline TE & .0060 & .026 & 2.308 & .0010 & .0110 & .020 & .0010 & .0110 & .020 \\
\hline TIE vs. DE & .0047 & .029 & 1.621 & -.0012 & .0103 & .109 & -.0011 & .0104 & .106 \\
\hline \multicolumn{10}{|l|}{ SIE } \\
\hline $\mathrm{S} 1 . \mathrm{RSL} \rightarrow \mathrm{NVG} \rightarrow \mathrm{L}_{\text {Aeq }}$ & -.0040 & .008 & 5.000 & -.0056 & -.0026 & .000 & -.0055 & -.0025 & .000 \\
\hline S2. $\mathrm{RSL} \rightarrow$ Speed $\rightarrow \mathrm{L}_{\text {Aeq }}$ & .0087 & .015 & 5.800 & .0058 & .0117 & .000 & .0057 & .0116 & .000 \\
\hline S3. RSL $\rightarrow$ NVG $\rightarrow$ Speed $\rightarrow$ Leq $_{\text {Aeq }}$ & .0007 & .003 & 2.333 & .0003 & .0013 & .000 & .0003 & .0013 & .000 \\
\hline \multicolumn{10}{|l|}{ Contrast between SIE } \\
\hline S1 vs.S2 & -.0127 & .019 & $\overline{6} .684$ & -.0167 & -.0091 & .000 & -.0165 & -.0089 & .000 \\
\hline S1 vs. S3 & -.0047 & .010 & 4.700 & -.0068 & -.0030 & .000 & -.0067 & -.0029 & .000 \\
\hline S2 vs. S3 & .0080 & .015 & 5.333 & .0051 & .0110 & .000 & .0051 & .0109 & .000 \\
\hline
\end{tabular}

Note. DE: direct effect; TIE: total indirect effect; TE: total effect; SIE: specific indirect effect; RSL: road segment length; NVG: number of vehicles in a group.

Table 8. Unstandardized direct effect (DE), total indirect effect (TIE), total effect (TE), and specific indirect effect (SIE) of road segment length (RSL) on $\mathrm{L}_{10}-\mathrm{L}_{90}$.

\begin{tabular}{|c|c|c|c|c|c|c|c|c|c|}
\hline \multirow[t]{2}{*}{$\mathrm{RSL} \rightarrow \mathrm{L}_{10}-\mathrm{L}_{90}$} & \multirow{2}{*}{$\begin{array}{l}\text { Point } \\
\text { Estimate }\end{array}$} & \multicolumn{2}{|c|}{$\begin{array}{l}\text { Product of } \\
\text { coefficients }\end{array}$} & \multicolumn{6}{|c|}{ Bootstrap 5,000 times $95 \% \mathrm{Cl}$} \\
\hline & & SE & $\mathrm{Z}$ & Lower & Upper & $p$ & Lower & Upper & $\mathrm{p}$ \\
\hline \multicolumn{10}{|l|}{ DE \& TIE \& TE } \\
\hline $\mathrm{DE}$ & -.0059 & .034 & -1.735 & -.0125 & .0010 & .089 & -.0127 & .0008 & .081 \\
\hline TIE & .0001 & .008 & .125 & -.0015 & .0016 & .902 & -.0015 & .0017 & .891 \\
\hline TE & -.0058 & .034 & -1.706 & -.0122 & .0010 & .101 & -.0125 & .0008 & .087 \\
\hline TIE vs. DE & .0060 & .036 & 1.667 & -.0012 & .0130 & .099 & -.0010 & .0131 & .091 \\
\hline \multicolumn{10}{|l|}{ SIE } \\
\hline S1. $R S L \rightarrow N V G \rightarrow L_{10}-L_{90}$ & .0017 & .004 & 4.250 & .0010 & .0027 & .000 & .0009 & .0026 & .000 \\
\hline S2. RSL $\rightarrow$ Speed $\rightarrow \mathrm{L}_{10}-\mathrm{L}_{90}$ & -.0015 & .007 & -2.143 & -.0031 & -.0003 & .018 & -.0030 & -.0002 & .028 \\
\hline S3. RSL $\rightarrow$ NVG $\rightarrow$ Speed $\rightarrow L_{10}{ }^{-} L_{90}$ & -.0001 & .001 & -1.000 & -.0003 & .0000 & .011 & -.0003 & .0000 & .028 \\
\hline \multicolumn{10}{|l|}{ Contrast between SIEs } \\
\hline S1 vs. S2 & .0032 & .009 & 3.556 & .0017 & .0051 & .000 & .0015 & .0050 & .000 \\
\hline S1 vs. S3 & .0018 & .005 & 3.600 & .0010 & .0029 & .000 & .0010 & .0028 & .000 \\
\hline S2 vs. S3 & -.0014 & .005 & -2.800 & -.0029 & -.0003 & .017 & -.0028 & -.0001 & .028 \\
\hline
\end{tabular}

Note. DE: direct effect; TIE: total indirect effect; TE: total effect; SIE: specific indirect effect; RSL: road segment length; NVG, number of vehicles in a group.

Table 8 lists the parameter estimates and confidence intervals for the effect of RSL on $L_{10}-L_{90}$. The TE, DE, and TIE of the RSL on $L_{10}-L_{90}$ are not significant. However, the three SIEs are significant. The two major SIEs occur in opposite directions and their effects are similar; thus, the TIE is not significant due to suppression effects. Each additional $10 \mathrm{~m}$ 
increases the group speed by $0.54 \mathrm{~km} / \mathrm{h}(\mathrm{BC} 95 \% \mathrm{Cl}[0.355,0.722])$, thereby reducing $\mathrm{L}_{10}-$ $\mathrm{L}_{90}$ by $0.015 \mathrm{~dB}(\mathrm{BC} 95 \% \mathrm{Cl}[-0.031,-0.003])$. Meanwhile, each additional $10 \mathrm{~m}$ reduces the NVG by 0.81 vehicles (BC $95 \% \mathrm{Cl}[-1.118,-0.505]$ ), thereby increasing $\mathrm{L}_{10}-\mathrm{L}_{90}$ by $0.017 \mathrm{~dB}(\mathrm{BC} 95 \% \mathrm{Cl}[0.010,0.027])$.

\subsection{Effect of road junction on noise}

Table 9 lists the parameter estimates and confidence intervals for the effect of RJ on $L_{\text {Aeq. }}$. The absence of traffic lights has a significant effect on the $L_{\text {Aeq }}$, which is $0.556 \mathrm{~dB}$ (BC $95 \% \mathrm{Cl}[0.056,1.060])$ higher than that in the presence of traffic lights. The DE and TIE are significant, with opposite effects, and the DE is significantly weaker than the TIE.

For the DE, noise in the absence of traffic lights is $0.561 \mathrm{~dB}$ lower than that in the presence of traffic lights (BC 95\% $\mathrm{Cl}[-1.012,-0.128]$ ), indicating that the installation of traffic lights can increase noise, independent of changes in the traffic flow. In the TIE, noise in the absence of traffic lights is $1.117 \mathrm{~dB}$ higher than that in the presence of traffic lights (BC 95\% Cl [0.828, 1.464]).

Table 9. Unstandardized direct effect (DE), total indirect effect (TIE), total effect (TE), and specific indirect effect (SIE) of road junction (RJ) on LAeq.

\begin{tabular}{|c|c|c|c|c|c|c|c|c|c|}
\hline \multirow{3}{*}{$\mathrm{RJ} \rightarrow \mathrm{L}_{\text {Aeq }}$} & \multirow{3}{*}{$\begin{array}{l}\text { Point } \\
\text { Estimate }\end{array}$} & \multirow{2}{*}{\multicolumn{2}{|c|}{$\begin{array}{l}\text { Product of } \\
\text { coefficients }\end{array}$}} & \multicolumn{6}{|c|}{ Bootstrap 5,000 times $95 \% \mathrm{Cl}$} \\
\hline & & & & \multicolumn{3}{|c|}{ Bias corrected } & \multicolumn{3}{|c|}{ Percentile } \\
\hline & & SE & $Z$ & Lower & Upper & $\mathrm{p}$ & Lower & Upper & $\mathrm{p}$ \\
\hline \multicolumn{10}{|l|}{ DE \& TIE \& TE } \\
\hline DE & -.561 & .223 & -2.516 & -1.012 & -.128 & .010 & -1.015 & -.129 & .009 \\
\hline TIE & 1.117 & .165 & 6.770 & .828 & 1.464 & .000 & .821 & 1.457 & .000 \\
\hline TE & .556 & .258 & 2.155 & .056 & 1.060 & .031 & .054 & 1.058 & .032 \\
\hline TIE vs. DE & 1.678 & .296 & 5.669 & 1.111 & 2.281 & .000 & 1.119 & 2.287 & .000 \\
\hline \multicolumn{10}{|l|}{ SIE } \\
\hline $\mathrm{S} 1 . \mathrm{RJ} \rightarrow \mathbf{N V G} \rightarrow \mathrm{L}_{\text {Aeq }}$ & .472 & .097 & 4.866 & .297 & .683 & .000 & .292 & .674 & .000 \\
\hline S2. $R J$ J Speed $\rightarrow L_{\text {Aeq }}$ & .727 & .164 & 4.433 & .432 & 1.076 & .000 & .429 & 1.068 & .000 \\
\hline S3. RJ $\rightarrow$ NVG $\rightarrow$ Speed $\rightarrow \mathrm{L}_{\text {Aeq }}$ & -.081 & .033 & -2.455 & -.164 & -.031 & .000 & -.159 & -.030 & .000 \\
\hline \multicolumn{10}{|l|}{ Contrast between SIEs } \\
\hline S1 vs. S2 & -.255 & .203 & -1.256 & -.664 & .130 & .194 & -.668 & .128 & .190 \\
\hline S1 vs. S3 & .552 & .125 & 4.416 & .335 & .829 & .000 & .327 & .819 & .000 \\
\hline S2 vs. S3 & .807 & .167 & 4.832 & .510 & 1.165 & .000 & .508 & 1.160 & .000 \\
\hline
\end{tabular}

Note. DE: direct effect; TIE: total indirect effect; TE: total effect; SIE: specific indirect effect; RJ: road junction; NVG: number of vehicles in a group.

Within the TIE, three SIEs are significant. In the pathway via the group speed, the absence of traffic lights increases the group speed by $4.52 \mathrm{~km} / \mathrm{h}(\mathrm{BC} 95 \% \mathrm{Cl}[2.789,6.365])$, thereby increasing the $L_{\text {Aeq }}$ by $0.727 \mathrm{~dB}(\mathrm{BC} 95 \% \mathrm{Cl}[0.432,1.076])$. In the pathway via the NVG, the absence of traffic lights increases the NVG by 9.49 vehicles (BC 95\% $\mathrm{Cl}[6.030$, 13.235]), thereby increasing the $L_{\text {Aeq }}$ by $0.472 \mathrm{~dB}$ (BC 95\% $\left.\mathrm{Cl}[0.297,0.683]\right)$.

Table 10 lists the parameter estimates and confidence intervals for the effect of $R J$ on $\mathrm{L}_{10}-\mathrm{L}_{90}$. The TE of the $R J$ on $\mathrm{L}_{10}-\mathrm{L}_{90}$ is significant, and noise in the absence of traffic lights is $1.652 \mathrm{~dB}(\mathrm{BC} 95 \% \mathrm{Cl}[-2.073,-1.225])$ lower than that in the presence of traffic lights. 
The DE and TIE are significant, and the DE is significantly stronger than the TIE. In terms of the $D E, L_{10}-L_{90}$ in the absence of traffic lights is $1.344 \mathrm{~dB}(\mathrm{BC} 95 \% \mathrm{Cl}[-1.766,-0.911])$ lower than that in the presence of traffic lights. In terms of the TIE, $\mathrm{L}_{10}-\mathrm{L}_{90}$ in the absence of traffic lights is $0.308 \mathrm{~dB}(\mathrm{BC} 95 \% \mathrm{Cl}[-0.466,-0.180])$ lower than that in the presence of traffic lights.

Within the TIE, three SIEs are significant. For the pathway via the group speed, the absence of traffic lights increases the speed by $4.52 \mathrm{~km} / \mathrm{h}(\mathrm{BC} 95 \% \mathrm{Cl}[2.789,6.365])$, thereby reducing $\mathrm{L}_{10}-\mathrm{L}_{90}$ by $0.124 \mathrm{~dB}(\mathrm{BC} 95 \% \mathrm{Cl}[-0.269,-0.021])$. For the pathway via the NVG, the absence of traffic lights increases the NVG by 9.49 vehicles $(\mathrm{BC} 95 \% \mathrm{Cl}$ $[6.030,13.235])$, thereby reducing $L_{10}-L_{90}$ by $0.198 \mathrm{~dB}(\mathrm{BC} 95 \% \mathrm{Cl}[-0.306,-0.122])$.

$R J$ has a significant direct effect on both $L_{A e q}$ and $L_{10}-L_{90}$, and will be analysed in the next section. However, the significant TIEs and SIEs of the RJ on the $L_{\text {Aeq }}$ and $L_{10}-L_{90}$ are more difficult to explain. This is likely due to the complex methods associated with traffic signal control. Therefore, further research is required.

Table 10. Unstandardized direct effect (DE), total indirect effect (TIE), total effect (TE), and specific indirect effect (SIE) of road junction (RJ) on L10-L90.

\begin{tabular}{|c|c|c|c|c|c|c|c|c|c|}
\hline \multirow{3}{*}{$\mathrm{RJ} \rightarrow \mathrm{L}_{10}-\mathrm{L}_{90}$} & \multirow{3}{*}{$\begin{array}{l}\text { Point } \\
\text { Estimate }\end{array}$} & \multirow{2}{*}{\multicolumn{2}{|c|}{$\begin{array}{l}\text { Product } \\
\text { coefficients }\end{array}$}} & \multicolumn{6}{|c|}{ Bootstrap 5,000 times $95 \% \mathrm{Cl}$} \\
\hline & & & & \multicolumn{3}{|c|}{ Bias corrected } & \multicolumn{3}{|c|}{ Percentile } \\
\hline & & SE & Z & Lower & Upper & $\mathrm{p}$ & Lower & Upper & $\mathrm{p}$ \\
\hline \multicolumn{10}{|l|}{ DE \& TIE \& TE } \\
\hline DE & -1.344 & .216 & -6.222 & -1.766 & -.911 & .000 & -1.766 & -.911 & .000 \\
\hline TIE & -.308 & .072 & -4.278 & -.466 & -.180 & .000 & -.457 & -.171 & .000 \\
\hline TE & -1.652 & .214 & -7.720 & -2.073 & -1.225 & .000 & -2.077 & -1.228 & .000 \\
\hline TIE vs. DE & 1.036 & .239 & 4.335 & .556 & 1.501 & .000 & .560 & 1.508 & .000 \\
\hline \multicolumn{10}{|l|}{ SIE } \\
\hline $\mathrm{S} 1 . \mathrm{RJ} \rightarrow \mathrm{NVG} \rightarrow \mathrm{L}_{10}-\mathrm{L}_{90}$ & -.198 & .046 & -4.304 & -.306 & -.122 & .000 & -.294 & -.113 & .000 \\
\hline S2. $R J \rightarrow$ Speed $\rightarrow \mathrm{L}_{10}-\mathrm{L}_{90}$ & -.124 & .063 & -1.968 & -.269 & -.021 & .020 & -.260 & -.013 & .028 \\
\hline S3. RJ $\rightarrow$ NVG $\rightarrow$ Speed $\rightarrow \mathrm{L}_{10}-\mathrm{L}_{90}$ & .014 & .008 & 1.750 & .003 & .037 & .014 & .001 & .033 & .028 \\
\hline \multicolumn{10}{|l|}{ Contrast between SIEs } \\
\hline S1 vs. S2 & -.075 & .078 & -.962 & -.217 & .091 & .342 & -.217 & .092 & .349 \\
\hline S1 vs. S3 & -.212 & .050 & -4.240 & -.331 & -.128 & .000 & -.317 & -.121 & .000 \\
\hline S2 vs. S3 & -.137 & .068 & -2.015 & -.293 & -.022 & .021 & -.285 & -.015 & .028 \\
\hline
\end{tabular}

\subsection{Paired comparisons of scenarios}

Paired comparison of scenarios use two methods: (1) microscopic traffic and noise simulation, and (2) macroscopic traffic simulation.

Five paired comparisons of scenarios were considered as typical examples to further validate the results through microscopic traffic and noise simulation, corresponding to the significant pathways (i.e., $L N \rightarrow$ speed $\rightarrow L_{\text {Aeq }}$ and $L_{10}-L_{90}, L N \rightarrow N V G \rightarrow L_{\text {Aeq }}$ and $L_{10}-L_{90}$, $\mathrm{RSL} \rightarrow$ speed $\rightarrow \mathrm{L}_{\text {Aeq }}$ and $\mathrm{L}_{10}-\mathrm{L}_{90}, \mathrm{RSL} \rightarrow \mathrm{NVG} \rightarrow \mathrm{L}_{\text {Aeq }}$ and $\mathrm{L}_{10}-\mathrm{L}_{90}$, and $\mathrm{RJ} \rightarrow \mathrm{L}_{\text {Aeq }}$, and $\left.\mathrm{L}_{10}-\mathrm{L}_{90}\right)$.

First, only one road characteristic indicator was assigned differently, excluding the influence of the other two indicators. Second, among the traffic flow indicators, only the 
mediated indicator could be changed according to the specified conditions, whereas the rest were fixed. Finally, microscopic traffic simulations were conducted, and traffic noise was calculated. The effect of $L N$ on traffic noise is illustrated by the paired comparison of two and five lanes. The effect of RSL on traffic noise is illustrated by the paired comparison of RSLs with lengths of 150 and $300 \mathrm{~m}$. The above pairings and other settings (see Table 11) can increase the effect of road characteristics on noise. It should be noted that to obtain a clearer trend, the scenario settings were not entirely based on the field measurement conditions.

Table 11. Setting details for five paired comparisons of scenarios in Vissim.

\begin{tabular}{|c|c|c|c|c|}
\hline \multirow[t]{2}{*}{ No. } & \multirow[t]{2}{*}{ Pathway } & \multirow{2}{*}{$\begin{array}{l}\text { Paired comparisons of } \\
\text { scenarios }\end{array}$} & \multicolumn{2}{|l|}{ Traffic flow variables } \\
\hline & & & Fixed indicator & Unfixed indicator \\
\hline 1 & $\begin{array}{l}\mathrm{LN} \rightarrow \quad \mathrm{NVG} \rightarrow \\
\mathrm{L}_{\text {Aeq }} / \mathrm{L}_{10}-\mathrm{L}_{90}\end{array}$ & $\begin{array}{l}\text { Paired comparison of two- } \\
\text { and five-lanes one-way, with } \\
\text { NVG unfixed, speed fixed, } \\
\text { and RSL of } 150 \mathrm{~m} \text {. }\end{array}$ & $\begin{array}{l}\text { Speed: set the road } \\
\text { speed limit to } 30 \mathrm{~km} / \mathrm{h} \text { via } \\
\text { Vissim. }^{\text {a }}\end{array}$ & $\begin{array}{l}\text { NVG: for two- and five- } \\
\text { lanes, set to } 7 \text { and } 54 \text {, } \\
\text { respectively. }{ }^{b}\end{array}$ \\
\hline 2 & $\begin{array}{l}\mathrm{LN} \rightarrow \quad \text { Speed } \rightarrow \\
\mathrm{L}_{\text {Aeq }} / \mathrm{L}_{10}-\mathrm{L}_{90}\end{array}$ & $\begin{array}{l}\text { Paired comparison of two- } \\
\text { and five-lanes one-way, with } \\
\text { speed unfixed, NVG fixed, } \\
\text { and RSL of } 150 \mathrm{~m} \text {. }\end{array}$ & NVG: set to $10 .^{c}$ & $\begin{array}{l}\text { Speed: obtained via } \\
\text { Vissim, according to the } \\
\text { car-following model. }\end{array}$ \\
\hline 3 & $\begin{array}{l}\mathrm{RSL} \rightarrow \mathrm{NVG} \rightarrow \\
\mathrm{L}_{\text {Aeq }} / \mathrm{L}_{10}-\mathrm{L}_{90}\end{array}$ & $\begin{array}{l}\text { Paired comparison of five- } \\
\text { lanes one-way with RSL of } \\
150 \text { and } 300 \mathrm{~m} \text {, NVG } \\
\text { unfixed, and speed fixed. }\end{array}$ & $\begin{array}{l}\text { Speed: set the road } \\
\text { speed limit to } 30 \mathrm{~km} / \mathrm{h} \text { via } \\
\text { Vissim. }^{a}\end{array}$ & $\begin{array}{l}\text { NVG: for RSL of } 150 \\
\text { and } 300 \mathrm{~m} \text {, set to } 24 \text { and } \\
\text { 10, respectively. }{ }^{d}\end{array}$ \\
\hline 4 & $\begin{array}{l}\mathrm{RSL} \rightarrow \text { speed } \rightarrow \\
\mathrm{L}_{\text {Aeq }} / \mathrm{L}_{10}-\mathrm{L}_{90}\end{array}$ & $\begin{array}{l}\text { Paired comparison of five- } \\
\text { lanes one-way with RSL of } \\
150 \text { and } 300 \mathrm{~m} \text {, speed } \\
\text { unfixed, and NVG fixed. }\end{array}$ & NVG: set to $24 .^{e}$ & $\begin{array}{l}\text { Speed: obtained via } \\
\text { Vissim, according to the } \\
\text { car-following model. }\end{array}$ \\
\hline 5 & $\mathrm{RJ} \rightarrow \mathrm{L}_{\text {Aeq }} / \mathrm{L}_{10}-\mathrm{L}_{90}$ & $\begin{array}{l}\text { Paired comparison of five- } \\
\text { lanes one-way } 150 \mathrm{~m} \text {, with or } \\
\text { without signal light in the } \\
\text { outgoing direction. }\end{array}$ & $\begin{array}{l}\text { Speed: set the road } \\
\text { speed limit to } 30 \mathrm{~km} / \mathrm{h} \text { via } \\
\text { Vissim. }^{\text {a }} \\
\text { NVG: set to } 24 \text {. }^{\text {e }}\end{array}$ & \\
\hline
\end{tabular}

Note. ${ }^{\text {a30 }} \mathrm{km} / \mathrm{h}$ is roughly the measured average speed, controlled by a "desired speed decision" in the Vissim simulation; ${ }^{b}$ To be as close as possible to the field measurement, NVG was set based on measured data: 7 is the average NVG of two-lanes and 54 is the average NVG of five-lanes; ' ${ }^{\circ}$ As close as possible to 7, which is the average NVG of two-lanes, while adhering to the group vehicle criteria, i.e., "the average number of vehicles per lane in the group is greater than one"; ${ }^{d}$ According to the result "each additional $10 \mathrm{~m}$ reduced the NVG by 0.81 vehicles," it can be estimated that the difference between RSL at 300 and $600 \mathrm{~m}$ is 12 . The NVG of $300 \mathrm{~m}$ RSL was set to 24 to make the effect that road characteristics had on noise more visible; ${ }^{e}$ Reference $\mathrm{d} ;{ }^{f}$ In the scenario without a signal light, a two-lane vertical road was set at the end of the road section as the priority traffic direction with 1,000 vehicles per hour.

Based on the methods used for field measurements, the receiving point was set in the middle of the road segment, data for each vehicle's driving status at each simulation time step was obtained, and traffic noise was calculated accordingly. Additionally, speed of the passage of each vehicle was recorded by a 'data collection point'. Finally, for each paired comparison of scenarios, the percent changes in the four indicators were calculated based on the four simulations, including the average passing vehicle speed $\left(\mathrm{V}_{\mathrm{avg}}\right)$, standard deviation of the passing vehicle speed $\left(V_{s d}\right), L_{\text {Aeq }}$, and $L_{10}-L_{90}$. The parameter $V_{s d}$ reflects the traffic flow stability (Jiang et al., 2017). Larger $V_{s d}$ values result in lower traffic flow stability and vice versa. An example of the scenario settings with a signal in paired comparison No. 5 is shown in Fig. 6. 
Signal light was required in all scenarios at the beginning and end of a road segment, except for scenarios where it was unable to be set. Signal lights at the beginning of a road segment are mainly meant to control the NVG by adjusting the signal timing. Signal lights placed at the end of a road segment have the same timing as the signals at the beginning of the road segment. The phase difference between the two signal lights is adjusted such that the vehicle encounters a red light when it reaches the end but all vehicles pass through during the next green light. The expected vehicle speed limit was set to $30 \pm 10 \mathrm{~km} / \mathrm{h}$ based on field measurement data. To obtain a more general conclusion, vehicles used for the traffic simulations were all light vehicles because the occurrence of heavy vehicles was too random. To collect a sufficient amount of vehicle data, calculations at a resolution of 10 time steps per simulation second were performed, with a duration of dozens of seconds depending on the traffic flow. A series of 0.1 -s resolution sound pressure levels were obtained from the simulations. $L_{A e q}, L_{10}, L_{50}$, and $L_{90}$ were then calculated.

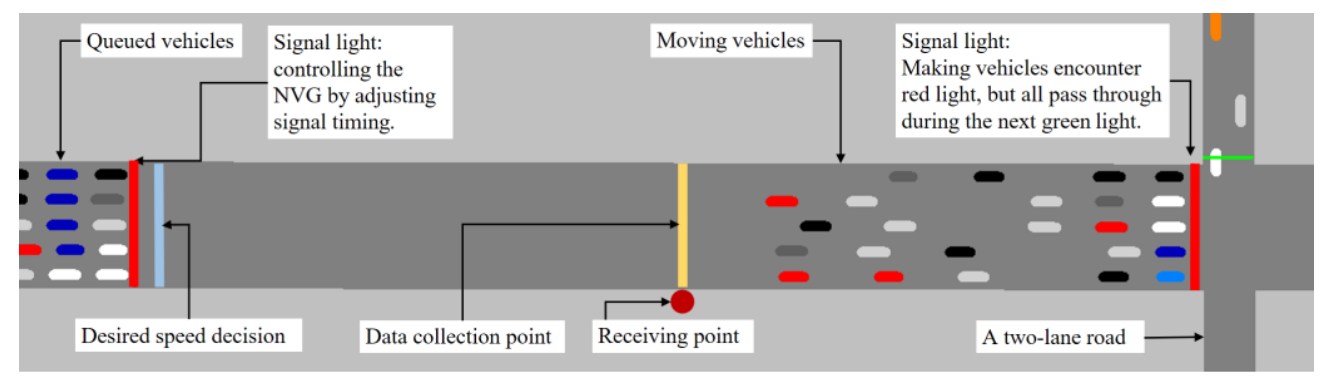

Fig. 6. Example scenario setting for paired comparison No. 5.

The units and ranges of the four indicators were not identical and cannot be directly compared. Thus, the percent change in each indicator for each paired comparison was discussed since the focus is to identify trends in the changes. As shown in Fig. 7, the trends in noise changes are consistent with previous conclusions based on statistical analysis. The specific analysis for each pathway is as follows.

The effect of $L N$ on $L_{\text {Aeq }}$ and $L_{10}-L_{90}$ via $N V G\left(L N \rightarrow N V G \rightarrow L_{\text {Aeq }}\right.$ and $\left.L_{10}-L_{90}\right)$ : based on the assumption that vehicle speed is fixed, an increase in the $L N$ increases the $L_{\text {Aeq, }}$, which is clearly due to the increase in the NVG, as shown in Fig. $7(a)$. The decrease in $L_{10}-L_{90}$ is caused by an increase in the NVG, which has a strong influence on background noise ( $\left.L_{90}\right)$ and a weak influence on peak noise $\left(L_{10}\right)$.

The effect of $L N$ on $L_{\text {Aeq }}$ and $L_{10}-L_{90}$ via speed $\left(L N \rightarrow\right.$ speed $\rightarrow L_{\text {Aeq }}$ and $\left.L_{10}-L_{90}\right)$ : based on the assumption that the NVG is fixed, an increase in the $L N$ increases $L_{\text {Aeq }}$ owing to the fact that the presence of more lanes enables higher speeds, which increases the noise levels, as shown in Fig. 7 (b). Meanwhile, $L_{10}-L_{90}$ decreases because as $V_{a v g}$ increases, abnormal driving behaviours, such as acceleration, deceleration, and lane-changing, decrease within the group, resulting in decreases in $\mathrm{V}_{\mathrm{sd}}$. This indicates that as vehicles travel more smoothly, traffic flow becomes more orderly and $L_{10}-L_{90}$ decreases. 


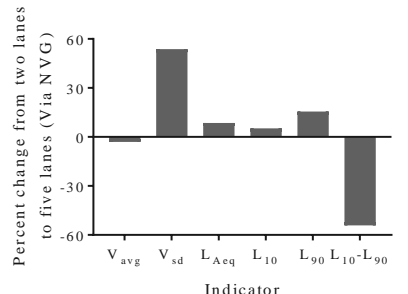

(a)

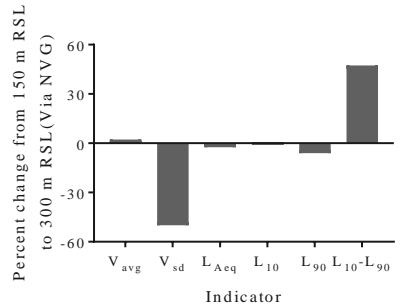

(c)

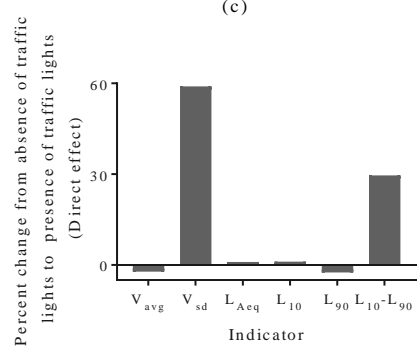

(e)

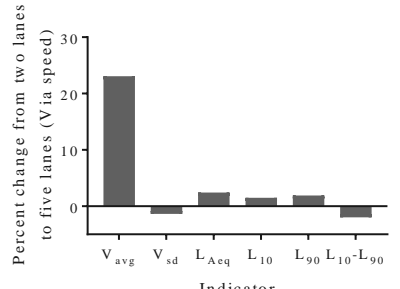

(b)

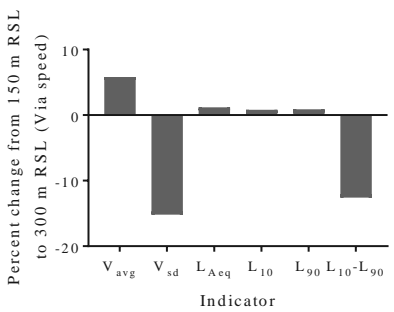

(d)

Fig. 7. Percent change in each indicator for each paired comparison of scenarios. (a) $L N \rightarrow N V G \rightarrow L_{\text {Aeq }}$ $\& \mathrm{~L}_{10}-\mathrm{L}_{90}$, (b) $\mathrm{LN} \rightarrow$ speed $\rightarrow \mathrm{L}_{\text {Aeq }} \& \mathrm{~L}_{10}-\mathrm{L}_{90}$, (c) $\mathrm{RSL} \rightarrow \mathrm{NVG} \rightarrow \mathrm{L}_{\text {Aeq }} \& \mathrm{~L}_{10}-\mathrm{L}_{90}$, (d) $\mathrm{RSL} \rightarrow$ speed $\rightarrow \mathrm{L}_{\text {Aeq }}$ $\& L_{10}-L_{90}$, and $(e) R J \rightarrow L_{\text {Aeq }} \& L_{10}-L_{90}$.

The effect of $R S L$ on $L_{\text {Aeq }}$ and $L_{10}-L_{90}$ via NVG $\left(R S L \rightarrow N V G \rightarrow L_{\text {Aeq }}\right.$ and $\left.L_{10}-L_{90}\right)$ : based on the assumption that the vehicle speed is fixed, an increase in the RSL increases the $L_{\text {Aeq, }}$, which is clearly due to the decrease in the NVG, as shown in Fig. 7(c). Meanwhile, $L_{10}-L_{90}$ also increases because the change in the NVG has different effects on the background $\left(L_{90}\right)$ and peak noise $\left(L_{10}\right)$.

The effect of $R S L$ on $L_{\text {Aeq }}$ and $L_{10}-L_{90}$ via speed $\left(R S L \rightarrow\right.$ speed $\rightarrow L_{\text {Aeq }}$ and $\left.L_{10}-L_{90}\right)$ : based on the assumption that NVG is fixed, an increase in the RSL increases the $L_{\text {Aeq }}$ because an increase in road length leads to increased group speed and noise, as shown in Fig. 7(d). The decrease in $L_{10}-L_{90}$ also indicates that changes in speed likely affect the orderliness of traffic flow, resulting in a decrease in $V_{\text {sd }}$.

The direct effect of $R J$ on $L_{\text {Aeq }}$ and $L_{10}-L_{90}\left(R J \rightarrow L_{\text {Aeq }}\right.$ and $\left.L_{10}-L_{90}\right)$ ): based on the assumption that NVG and speed are fixed, the presence of traffic lights increases the $L_{\text {Aeq }}$ because traffic lights are more likely to encourage the driver to accelerate or decelerate (as applicable) and drastically increase the $\mathrm{V}_{\text {sd }}$, thereby generating more noise, as shown in Fig. $7(\mathrm{e})$. The presence or deceleration leads to considerable disorder in the vehicle driving state, as well as an increase in $L_{10}-L_{90}$. 
Furthermore, the results were explored using control delay. HCS can accurately obtain control delay, but it is difficult to obtain the corresponding noise levels. Therefore, using the control delay as the independent variable instead of noise indicators in each pathway, paired comparisons of scenarios were considered as typical examples in HCS. In this way, the delay obtained by HCS simulation can be compared with the noise level obtained by statistical analysis, and the relationship between delay and noise can be determined.

Among five significant pathways, there were two pathways $(\mathrm{LN} \rightarrow$ Speed $\rightarrow$ Delay and $R J \rightarrow$ Delay) that could be analysed for control delay. The effects of RSL on the delay can be varied by the signal cycle and were therefore not analysed. For example, even with different RSL, minimally delayed traffic flow can be achieved in one direction through a series of coordinated traffic lights (i.e., green waves). The pathways via NVG were not analysed as well, partly because the indicator that reflects traffic volume in HCS is flow rate $(v e h / h)$ instead of $N V G$, which cannot be estimated from the changing road characteristics in this study; partly because the speed cannot be accurately fixed in HCS.

The All-Way Stop-Controlled (AWSC) module was used for the scenario of a road junction without traffic lights (i.e., a non-signalized intersection), and the Streets module was used for other scenarios in HCS. The road speed limit was uniformly set at $60 \mathrm{~km} / \mathrm{h}$, and running speed was automatically calculated according to a platoon dispersion mode (Forde and Daniel, 2017). All signals cycles were 80s and completely synchronous, and the duration of the green light and yellow light for the study road was always set to a half cycle. The other settings in the scenario were as follows: one-way road, no slope, no heavy vehicle, 0.25-h analysis duration (Table. 12). The flow rates in the scenarios were set to three conditions, while ensuring control delays of less than $40 \mathrm{~s} / \mathrm{veh}$, meaning that LOS at intersections ranged from level $A$ to level $D$, which is the acceptable level range. The average control delay was calculated under three conditions for each scenario. Then, the percent change of control delay for each paired comparison was discussed, as shown in Fig. 8. Specific analysis for each pathway is as follows.

Table 12. Setting details for two paired comparisons of scenarios in the Highway Capacity Software (HCS).

\begin{tabular}{|c|c|c|c|c|}
\hline \multirow[t]{2}{*}{ No. } & \multirow[t]{2}{*}{ Pathway } & \multirow{2}{*}{$\begin{array}{l}\text { Paired comparison } \\
\text { scenarios }\end{array}$} & \multicolumn{2}{|l|}{ Traffic flow variables } \\
\hline & & & Fixed indicator & Unfixed indicator \\
\hline 1 & $\begin{array}{l}\mathrm{LN} \rightarrow \text { Speed } \rightarrow \\
\text { Delay }\end{array}$ & $\begin{array}{l}\text { Paired comparison of two- } \\
\text { and five-lanes one-way, with } \\
\text { flow rate fixed, speed } \\
\text { unfixed, and road segment } \\
\text { length (RSL) of } 150 \mathrm{~m} \text {. }\end{array}$ & $\begin{array}{l}\text { Flow rate: set to } 1000 \text {, } \\
1400,1800 \text { veh/h for } \\
\text { each road, respectively. }\end{array}$ & $\begin{array}{l}\text { Speed: obtained via } \\
\text { HCS, according to a } \\
\text { platoon dispersion } \\
\text { mode. }\end{array}$ \\
\hline 2 & $\mathrm{RJ} \rightarrow$ Delay & $\begin{array}{l}\text { Paired comparison of two- } \\
\text { lanes one-way, with or } \\
\text { without signal light. Another } \\
\text { perpendicular one-lane road } \\
\text { set at intersection. }\end{array}$ & $\begin{array}{l}\text { Flow rate: set to } 400 \text {, } \\
500,600 \text { veh/h for each } \\
\text { lane, respectively. } \\
\text { Speed: Models do not } \\
\text { contain segment, no } \\
\text { interval speed }\end{array}$ & \\
\hline
\end{tabular}


The effect of $L N$ on delay via speed $(\mathrm{LN} \rightarrow$ Speed $\rightarrow$ Delay): based on the assumption that traffic volume is fixed, increasing $L N$ will reduce the delay and increase the $L_{\text {Aeq }}$, as shown in Fig. 8(a). This is consistent with analysis of Vissim simulations, and is because the increase in LN increases the road capacity, reducing the delay (average control delay reduced from 17.2 to $9.5 \mathrm{~s} /$ veh), which in turn increases the speed (average running speed increased from 40.5 to $43.2 \mathrm{~km} / \mathrm{h}$ ) and noise.

The direct effect of $R J$ on delay (RJ $\rightarrow$ Delay): based on the assumption that traffic volume and speed are fixed, the presence of traffic lights will reduce delay, and increase the $L_{\text {Aeq, }}$ as shown in Fig. $8(\mathrm{~b})$. This is consistent with the analysis of Vissim simulations, and is because setting a traffic light will enhance the road capacity and reduce delays (average control delay reduced from 25.4 to $17.4 \mathrm{~s} / \mathrm{veh}$ ), while encouraging vehicle acceleration and deceleration in the middle of the road segment, which in turn increases noise, since traffic lights allows a driver to judge the junction situation in advance.

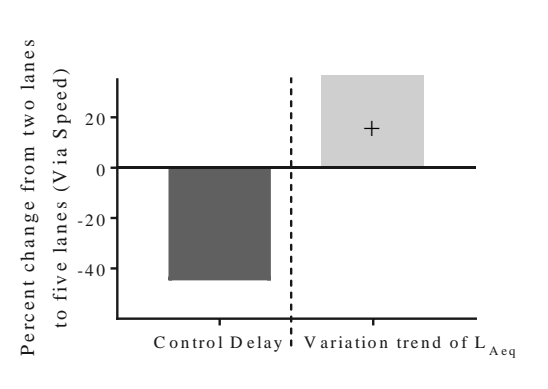

(a)

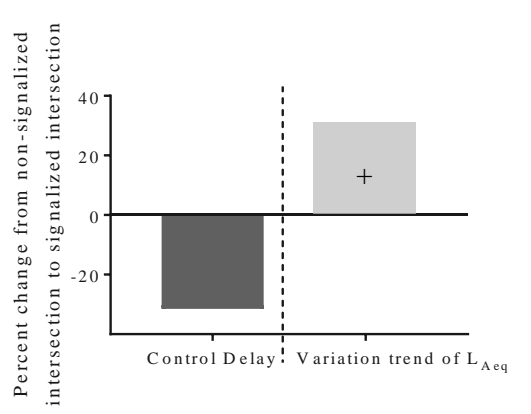

(b)

Fig. 8. Percent change in control delay for each paired comparison of scenarios. (a) $L N \rightarrow$ speed $\rightarrow$ Delay, (b) RJ $\rightarrow$ Delay.

Besides confirming the results obtained from statistical analysis, the macroscopic traffic simulation also found that reducing delays tends to increase noise intensity in the middle of the road segment. This relationship may change with location, for example, previous research found that in the sections of adjacent road junction, the greater the delay, the greater the noise intensity (Pal and Sarkar, 2012).

\section{Discussion}

Urban planning in China is paying more and more attention to traffic noise. Since 2009, the Chinese government has mandated planning design achievements, mainly including regulatory- and constructive-detailed planning, to allow for planning of environmental impact assessments (PEIA), within which traffic noise is one of the evaluation components. However, traffic noise is still rarely considered in urban planning and design in China. The PEIA only evaluates traffic noise planning achievements and proposes general suggestions, with minimal interaction with urban planners. Moreover, unlike Europe (Alves 
et al., 2016), most cities do not have noise maps and suitable sound planning tools, which makes it difficult for planners to consider traffic noise during the planning design stage.

The influencing mechanism determined in this study can help planners better understand the relationships between road networks and traffic noise. For example, based on our results, each additional lane increases the average NVG of each lane by approximately $50 \%$, which shows that the pathway through the NVG has the greatest LN effect on traffic noise. This is because traffic organisation and management actively guides vehicles into higher hierarchy roads, largely characterised by $L N$, to achieve improved vehicle flow with higher speeds and less congestion.

The parameter estimates reported in this study can be used as a local noise estimation model. In the urban planning stage, this type of model can help traffic noise assessments through an analysis of design information rather than complex acoustic calculations and simulations. For example, for the current scenario (i.e., road segment No.13 as shown in Fig. 9a), if the road characteristics change, the noise value can be predicted for local urban planning according to the total effect reported in this study. The road is cancelled, and thus the length of the segment increases by $150 \mathrm{~m}$, as shown in Fig. $9(\mathrm{~b})$, $\mathrm{L}_{\text {Aeq }}$ increases by 0.9 $\mathrm{dB}\left(0.0060^{*} 150\right)$, and $\mathrm{L}_{10}-\mathrm{L}_{90}$ decreases by $0.87 \mathrm{~dB}\left(0.0058^{*} 150\right)$. The traffic signal in the driving direction is further cancelled, such that $L_{\text {Aeq }}$ decreases by $0.6 \mathrm{~dB}$ and $L_{10}-L_{90}$ increases by $1.6 \mathrm{~dB}$, as shown in Fig. 9(c).

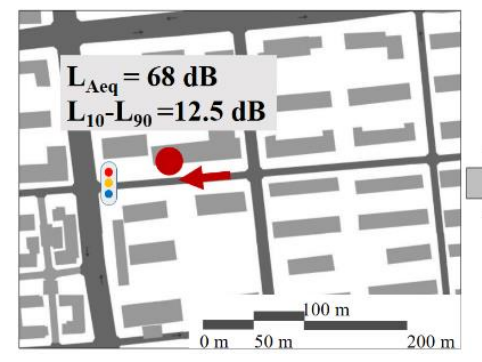

(a)

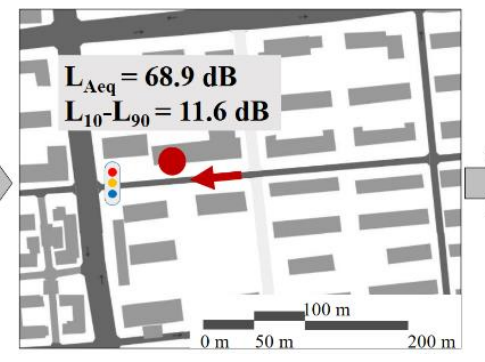

(b)

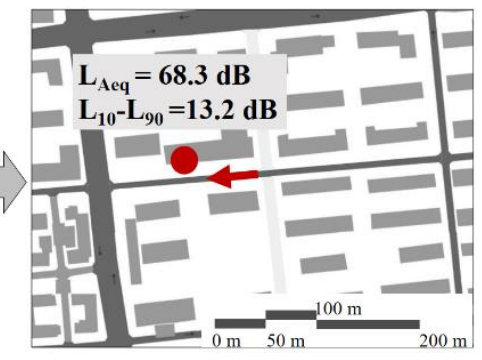

(c)

Fig. 9. Example of noise estimation for changes in road characteristics. (a) Current scenario of the road network and measured average noise value; (b) scenario with the cancelation of a vertical road along with the corresponding noise estimation; and (c) scenario with the cancelation of a vertical road and traffic light along with the corresponding noise estimation.

In addition, this study can also help amend PEIA predictions based on the road characteristics. In China, traffic noise PEIAs mostly use commercial noise prediction software. Detailed traffic flow data is a prerequisite for accurate simulations, which is difficult to obtain in China. China's road network is changing rapidly and many urban planning projects are faced with undeveloped land. Owing to the large gap between existing and future traffic data, PEIAs usually rely on forecast data for a certain period in the future $(5,10$, or 20 years $)$. For a long-distance road, the assigned traffic data and traffic 
noise predictions are often identical. With the discussion provided in this study and through the analysis of design information, prediction results can be modified based on the road characteristics, allowing for more accurate urban planning initiatives.

\section{Conclusions}

In this study, the influence of road characteristics on traffic noise with traffic flow as a mediator was investigated using field noise measurements along typical road segments in China. Microscopic and macroscopic traffic simulations for paired comparisons of scenarios, were performed to conform to the needs of urban planning. The results show that:

1) The greatest effect of the lane number on traffic noise is the pathway through the number of vehicles in a group. A higher number of lanes indicates greater traffic demand due to more connected urban land, with a resulting increase in traffic volume and noise intensity. This has a strong and weak influence on background noise ( L90 $_{90}$ and peak noise $\left(L_{10}\right)$, respectively, thereby decreasing noise amplitude.

2) The effect that the RSL has on traffic noise mainly depends on the suppression effect. An increase in road length results in higher vehicle speed, leading to higher noise intensity and reduced noise amplitude. Simultaneously, an increase in the road length leads to a smaller number of vehicles in a group, which reduces noise intensity and increases noise amplitude.

3) Road junctions, which are classified according to the presence or absence of traffic lights, have a significant direct effect on both noise intensity and amplitude. The presence of traffic lights increases noise intensity because they are more likely to encourage drivers to accelerate or decelerate in the middle of the road segment. The acceleration and deceleration associated with traffic lights leads to considerable disorder in a vehicle's momentum, which increases noise amplitude.

\section{Acknowledgments}

The authors are indebted to Hang An, Xidong Liu, and Lin Yang for assistance with the field survey in Dalian. This work was supported by the State Natural Science Foundation of China [grant numbers 51878110, 51778099, and 51778100].

\section{References}

Alves, S., Scheuren, J., Altreuther, B. (2016). Review of recent EU funded research projects from the perspective of urban sound planning: Do the results cope with the needs of Europe's noise policy. Noise Mapp, 3, 86-106. 
Barrigón Morillas, J. M., Gómez Escobar, V., Sierra, J. A., Vilchez-Gómez, R., Vaquero, J. M., \& Carmona, J. T. (2005). A categorization method applied to the study of urban road traffic noise. The Journal of the Acoustical Society of America, 117(5), 2844-2852. https://doi.org/10.1121/1.1889437

Barrigón Morillas, J. M., Montes González, D., \& Rey Gozalo, G. (2016). A review of the measurement procedure of the ISO 1996 standard. Relationship with the European Noise Directive. Science of The Total Environment, 565, 595-606. https://doi.org/10.1016/j.scitotenv.2016.04.207

Bartels, R. (1982). The rank version of von Neumann's ratio test for randomness. Journal of the American Statistical Association, 77(377), 40-46. https://doi.org/10.1080/01621459.1982.10477764

Can, A., Leclercq, L., Lelong, J., \& Defrance, J. (2008). Capturing urban traffic noise dynamics through relevant descriptors. Applied Acoustics, 69(12), 1270-1280. https://doi.org/10.1016/j.apacoust.2007.09.006

Cohen, J. (1988). Statistical power analysis for the behavioral sciences (2nd ed.). Hillsdale, NJ: Lawrence Erlbaum Associates.Page:83

D'Alessandro, F., Asdrubali, F., \& Schiavoni, S. (2014). The noise abatement plan of an Italian road network: a comparison between standard and innovative methodologies. The Open Transportation Journal, 8, 26-38.

Estévez-Mauriz, L., Forssén, J. (2018). Dynamic traffic noise assessment tool: A comparative study between a roundabout and a signalised intersection. Applied Acoustics, 130, 71-86.

EEA (European Environment Agency). (2014). Noise in Europe 2014. EEA Report No. 10/2014. Luxembourg: Publications Office of the European Union.

Fellendorf M., Vortisch P. (2010) Microscopic Traffic Flow Simulator VISSIM. In: Barceló J. (eds) Fundamentals of Traffic Simulation. International Series in Operations Research \& Management Science, vol 145. Springer, New York, NY.

Forde, A., \& Daniel, J. (2017). Performance evaluation of the HCM 2010 platoon dispersion model under midblock pedestrian and truck traffic friction conditions. Journal of Traffic and Transportation Engineering (English Edition), 4(6), 522-534. https://doi: 10.1016/j.jtte.2017.04.003

Fritschi, L., Brown, A. L. Kim, R., Schwela, D., \& Kephalopoulos, S. (2011). Conclusion. In F. Theakston (Ed.), Burden of disease from environmental noise: Quantification of healthy life years lost in Europe (pp. 99-105). Copenhagen: WHO Regional Office for Europe.

Fyhri, A., \& Klæboe, R. (2009). Road traffic noise, sensitivity, annoyance and self-reported health—A structural equation model exercise. Environment International, $35(1), \quad 91-97$. https://doi.org/10.1016/j.envint.2008.08.006

Garg, N. \& Maji, S. (2014). A critical review of principal traffic noise models: Strategies and implications. Environmental Impact Assessment Review, 46(3), 68-81. https://doi.org/10.1016/j.eiar.2014.02.001

Gardziejczyk, W., Motylewicz, M. (2016). Noise level in the vicinity of signalized roundabouts. Transportation Research Part D: Transport and Environment, 46, 128-144.

Golmohammadi, R., Abbaspour, M, Nassiri, P., Mahjub, H. (2009). A compact model for predicting road traffic noise. Iranian Journal of Environmental Health Science \& Engineering. 6(3), 181 -186.

Halonen, J.I., et al. (2015). Road traffic noise is associated with increased cardiovascular morbidity and mortality and all-cause mortality in London. European Heart Journal. 36(39), 2653-2661. https://doi.org/10.1093/eurheartj/ehv216

Hayes, A. F. (2009). Beyond Baron and Kenny: Statistical mediation analysis in the new millennium. Communication Monographs, 76(4), 408-420. https://doi.org/10.1080/03637750903310360

Hayes, A. F. (2013). Introduction to mediation, moderation, and conditional process analysis: A regression-based approach. New York: Guilford Publications.

Holbert, R. L., \& Stephenson, M. T. (2003). The importance of indirect effects in media effects research: Testing for mediation in structural equation modelling. Journal of Broadcasting \& Electronic Media, 47(4), 556-572. https://doi.org/10.1207/s15506878jobem4704_5

Hong, J.Y., \& Jeon, J.Y. (2015). Influence of urban contexts on soundscape perceptions: A structural equation modeling approach. Landscape and Urban Planning, 141(9), 78-87. https://doi.org/10.1016/j.landurbplan.2015.05.004

$\mathrm{Hu}$, L., \& Bentler, P. M. (1999). Cutoff criteria for fit indexes in covariance structure analysis: Conventional criteria versus new alternatives. Structural Equation Modeling: A Multidisciplinary Journal, 6(1), 1-55. https://doi.org/10.1080/10705519909540118

lannone, G., Guarnaccia, C., \& Quartieri, J. (2013). Speed distribution influence in road traffic noise prediction. Environmental Engineering and Management Journal, 12(3), 493-501.

Li, F., Lin, Y., Cai, M., Du, C. (2017). Dynamic simulation and characteristics analysis of traffic noise at roundabout and signalized intersections. Applied Acoustics, 121(6): 14-24.

ISO (International Organization for Standardization). (1996). Acoustics - attenuation of sound during propagation outdoors - Part 2: General method of calculation (ISO 9613-2)

ISO (International Organization for Standardization). (2017). Description, measurement and assessment of environmental noise. Part 2: determination of environmental noise levels (ISO 1996-2).

Jackson, D. L., Gillaspy, J. A., \& Purc-Stephenson, R. (2009). Reporting practices in confirmatory factor analysis: An overview and some recommendations. Psychological Methods, 14(1), 6-23. http://dx.doi.org/10.1037/a0014694

Jiang, R., Jin, C.J., Zhang, H.M., Huang, Y.X., Tian, J.F., Wang, W., Hu, M.B., Wang, H., Jia, B. (2017). Experimental and empirical investigations of traffic flow instability. Transportation Research Procedia. 23, 157-173. 
MEP (Ministry of Environmental Protection). (2018). China Environmental Noise Prevention and Control Annual Report. Beijing, (in Chinese).

MEP (Ministry of Environmental Protection). (2017). China Environmental Noise Prevention and Control Annual Report. Beijing, (in Chinese).

Muaz, M., Tang, S. K., Lin, T. C., \& Ng, H. T. (2017). Fitting "bad urban" roadside motor traffic sound level to skewed distribution models. In Proceeding of Inter-noise 2017 Hong Kong, China, (pp. 1513-1518).

Naish, D. (2010). A method of developing regional road traffic noise management strategies. Applied Acoustics, 71(7), 640-652. https://doi.org/10.1016/j.apacoust.2010.02.009

Ouis, D., (2001). Annoyance from road traffic noise: A review. Journal of Environmental Psychology, 21(1), 101-120. https://doi.org/10.1006/jevp.2000.0187

Pal, M., \& Sarkar, D., (2012). Delay, fuel loss and noise pollution during idling of vehicles at signalized intersection in Agartala city, India. Civil and Environmental Research 2(6), 161-170

Parker, M. T. (1996). The effect of heavy goods vehicles and following behaviour on capacity at motorway roadwork sites. Traffic Engineering \& Control, 37(9), 524-531.

Preacher, K. J., \& Hayes, A. F. (2008). Asymptotic and resampling strategies for assessing and comparing indirect effects in multiple mediator models. Behavior Research Methods, 40(3), 879-891. https://doi.org/10.3758/BRM.40.3.879

Puan, O. C. (2004). Driver's car following headway on single carriageway roads. Malaysian Journal of Civil Engineering, 16(2), 15-27.

Rey Gozalo, G., Barrigón Morillas, J. M., \& Gómez Escobar, V. (2013). Urban streets functionality as a tool for urban pollution management. Science of The Total Environment. 461, 453-461. https://doi.org/10.1016/j.scitotenv.2013.05.017

Ruiz-Padillo, A., Torija, A. J., Ramos-Ridao, Á., \& Ruiz, D. P. (2014). A methodology for classification by priority for action: Selecting road stretches for network noise action plans. Transportation Research Part D: Transport and Environment. 29, 66-78. https://doi.org/10.1016/j.trd.2014.04.002

Ryu, H., Park, I. K., Chun, B. S., \& Chang, S. I. (2017). Spatial statistical analysis of the effects of urban form indicators on road-traffic noise strength of a city in South Korea. Applied Acoustics, 115(1), 93-100. https://doi.org/10.1016/j.apacoust.2016.08.025

Salomons, E. M., \& Pont, M. B. (2012). Urban traffic noise and the relation to urban density, form, and traffic elasticity. Landscape and Urban Planning, 108(1), 2-16. https://doi.org/10.1016/j.landurbplan.2012.06.017

SCU (Science Communication Unit), (2017). Science for Environment Policy, Noise abatement approaches. Future Brief 17. European Commission DG Environment. http://ec.europa.eu/science-environment-policy

Sheng, N., \& Tang, U. W. (2011). Spatial analysis of urban form and pedestrian exposure to traffic noise. International Journal of Environmental Research and Public Health, 8(6), 1977-1990. https://doi.org/10.3390/ijerph8061977

Stansfeld, S.A., et al. (2005). Aircraft and road traffic noise and children's cognition and health: a cross-national study. The Lancet, 365(9475), 1942-1949. https://doi.org/10.1016/S0140-6736(05)66660-3

Tang, U. W., \& Wang, Z. S. (2007). Influences of urban forms on traffic-induced noise and air pollution: Results from a modelling system. Environmental Modelling \& Software, 22(12), 1750-1764. https://doi.org/10.1016/j.envsoft.2007.02.003

Transportation Research Board (TRB), (2010). Highway Capacity Manual 6th. National Research Council, Washington DC.

Van Kempen, E., \& Babisch, W. (2012). The quantitative relationship between road traffic noise and hypertension: a meta-analysis. Journal of hypertension, 30(6), 1075-1086. https://doi.org/10.1097/hjh.0b013e328352ac54

Wald, A., \& Wolfowtiz, J. (1940). On a test whether two samples are form the same population. Annals of Mathematical Statistics, 11(2), 147-162. https://doi.org/10.1214/aoms/1177731909

Wang, B., \& Kang, J. (2011). Effects of urban morphology on the traffic noise distribution through noise mapping: A comparative study between UK and China. Applied Acoustics, 72(8), 556-568. https://doi.org/10.1016/j.apacoust.2011.01.011

Wu, J. J., Sun, H. J., \& Gao, Z. Y. (2008). Dynamic urban traffic flow behavior on scale-free networks. Physica $A$ Statistical Mechanics and its Applications, 387(2-3), 653-660. https://doi.org/10.1016/j.physa.2007.09.020

Williams, K. M., Stover, V. G., Dixon, K. K., \& Demosthenes, P. (2014). Access management manual (2nd ed.). Washington, DC: National Academy of Sciences.

Yang, W., \& Kang, J. (2005). Acoustic comfort evaluation in urban open public spaces. Applied Acoustics, 66(2), 211229. https://doi.org/10.1016/j.apacoust.2004.07.011.

Yazici, M.A., Kocatepe, A., \& Ozguven, E.E., (2017). Breakdown of weather, intersection and recurrent congestion impacts on urban delay in New York City. Transportation Research Procedia 22, 399-408. https://doi.org/10.1016/j.trpro.2017.03.009 
Table A.1. The runs test for each measurement point

\begin{tabular}{|c|c|c|c|c|c|c|c|c|c|}
\hline \multicolumn{2}{|c|}{ Road Name } & \multirow{2}{*}{$\begin{array}{l}\text { NVG } \\
108.0000000\end{array}$} & \multirow{2}{*}{$\begin{array}{l}\text { Speed } \\
24.5800000\end{array}$} & \multirow{2}{*}{$\begin{array}{l}\text { HVP } \\
.0700000\end{array}$} & \multirow{2}{*}{$\begin{array}{l}\text { LAeq } \\
74.2000000\end{array}$} & \multirow{2}{*}{$\begin{array}{l}\text { L10 } \\
76.5000000\end{array}$} & \multirow{2}{*}{$\begin{array}{l}\text { L50 } \\
73.3000000\end{array}$} & \multirow{2}{*}{$\begin{array}{l}\text { L90 } \\
70.5000000\end{array}$} & \multirow{2}{*}{$\begin{array}{l}\text { L10-L90 } \\
6.0000000\end{array}$} \\
\hline NO.01- & Test Value $^{a}$ & & & & & & & & \\
\hline ZS & Cases $<$ Test Value & 19 & 19 & 15 & 18 & 18 & 19 & 19 & 19 \\
\hline & Cases $>==$ Test Value & 20 & 20 & 24 & 21 & 21 & 20 & 20 & 20 \\
\hline & Total Cases & 39 & 39 & 39 & 39 & 39 & 39 & 39 & 39 \\
\hline & Number of Runs & 15 & 15 & 24 & 21 & 22 & 18 & 16 & 22 \\
\hline & z & -1.620 & -1.620 & 1.387 & .038 & .364 & -.645 & -1.295 & .329 \\
\hline & Asymp. Sig. (2-tailed) & .105 & .105 & .166 & .970 & .716 & .519 & .195 & .742 \\
\hline$\overline{\mathrm{NO} .02-}$ & Test Value $^{\text {a }}$ & 4.0000000 & 35.0100000 & $.0000000^{b}$ & 71.3000000 & 73.0000000 & 71.0000000 & 69.1000000 & 4.7000000 \\
\hline $\mathrm{FN}$ & Cases $<$ Test Value & 20 & 19 & 0 & 20 & 19 & 20 & 20 & 20 \\
\hline & Cases $>=$ Test Value & 21 & 22 & 41 & 21 & 22 & 21 & 21 & 21 \\
\hline & Total Cases & 41 & 41 & 41 & 41 & 41 & 41 & 41 & 41 \\
\hline & Number of Runs & 16 & 20 & $1^{\mathrm{b}}$ & 19 & 25 & 18 & 16 & 21 \\
\hline & z & -1.579 & -.283 & & -.629 & .989 & -.946 & -1.579 & .000 \\
\hline & Asymp. Sig. (2-tailed) & .114 & .777 & & .529 & .323 & .344 & .114 & 1.000 \\
\hline$\overline{\mathrm{NO} .03-}$ & Test Value $^{\mathrm{a}}$ & 58.5000000 & 38.4650000 & .1100000 & 74.4500000 & 76.8500000 & 73.0000000 & 68.3500000 & 8.4000000 \\
\hline TY & Cases $<$ Test Value & 20 & 20 & 16 & 20 & 20 & 19 & 20 & 18 \\
\hline & Cases $>=$ Test Value & 20 & 20 & 24 & 20 & 20 & 21 & 20 & 22 \\
\hline & Total Cases & 40 & 40 & 40 & 40 & 40 & 40 & 40 & 40 \\
\hline & Number of Runs & 17 & 18 & 16 & 21 & 23 & 21 & 23 & 25 \\
\hline & z & -1.121 & -.801 & -1.236 & .000 & .481 & .000 & .481 & 1.198 \\
\hline & Asymp. Sig. (2-tailed) & .262 & .423 & .216 & 1.000 & .631 & 1.000 & .631 & .231 \\
\hline NO.04- & Test Value $^{a}$ & $2.0000000^{6}$ & 35.0350000 & $.0000000^{\circ}$ & 69.4500000 & 72.5000000 & 68.0500000 & 65.3000000 & 8.7500000 \\
\hline $\mathrm{JX}$ & Cases $<$ Test Value & 0 & 3 & 0 & 3 & 3 & 3 & 3 & 3 \\
\hline & Cases $>=$ Test Value & 6 & 3 & 6 & 3 & 3 & 3 & 3 & 3 \\
\hline & Total Cases & 6 & 6 & 6 & 6 & 6 & 6 & 6 & 6 \\
\hline & Number of Runs & $1^{\mathrm{c}}$ & 5 & $1^{\mathrm{c}}$ & 5 & 5 & 5 & 3 & 4 \\
\hline & z & & .456 & & .456 & .456 & .456 & -.456 & .000 \\
\hline & Asymp. Sig. (2-tailed) & & .648 & & .648 & .648 & .648 & .648 & 1.000 \\
\hline NO.05- & Test Value $^{\text {a }}$ & 43.0000000 & 31.8100000 & .1000000 & 73.3500000 & 75.4500000 & 72.0500000 & 68.8000000 & 6.9500000 \\
\hline FF1 & Cases $<$ Test Value & 18 & 18 & 17 & 18 & 18 & 18 & 17 & 18 \\
\hline & Cases $>=$ Test Value & 18 & 18 & 19 & 18 & 18 & 18 & 19 & 18 \\
\hline & Total Cases & 36 & 36 & 36 & 36 & 36 & 36 & 36 & 36 \\
\hline & Number of Runs & 8 & 18 & 17 & 18 & 19 & 15 & 19 & 15 \\
\hline & z & -3.551 & -.169 & -.490 & -.169 & .000 & -1.184 & .000 & -1.184 \\
\hline & Asymp. Sig. (2-tailed) & .000 & .866 & .624 & .866 & 1.000 & .237 & 1.000 & .237 \\
\hline NO.06- & Test Value $^{\text {a }}$ & 54.5000000 & 33.8500000 & .0700950 & 75.1000000 & 77.7000000 & 74.0000000 & 69.3500000 & 8.5500000 \\
\hline GRJ1 & Cases $<$ Test Value & 28 & 27 & 28 & 27 & 26 & 27 & 28 & 28 \\
\hline & Cases $>=$ Test Value & 28 & 29 & 28 & 29 & 30 & 29 & 28 & 28 \\
\hline & Total Cases & 56 & 56 & 56 & 56 & 56 & 56 & 56 & 56 \\
\hline & Number of Runs & 16 & 26 & 26 & 25 & 24 & 23 & 25 & 31 \\
\hline & z & -3.506 & -.801 & -.809 & -1.071 & -1.317 & -1.611 & -1.079 & .539 \\
\hline & Asymp. Sig. (2-tailed) & .000 & .423 & .418 & .284 & .188 & .107 & .281 & .590 \\
\hline NO.07- & Test Value $^{a}$ & 22.0000000 & 29.2550000 & .0850000 & 72.6500000 & 74.9000000 & 71.7500000 & 67.6500000 & 7.3500000 \\
\hline BS2 & Cases $<$ Test Value & 17 & 18 & 18 & 18 & 18 & 18 & 18 & 18 \\
\hline & Cases $>=$ Test Value & 19 & 18 & 18 & 18 & 18 & 18 & 18 & 18 \\
\hline & Total Cases & 36 & 36 & 36 & 36 & 36 & 36 & 36 & 36 \\
\hline & Number of Runs & 14 & 12 & 23 & 17 & 21 & 15 & 20 & 22 \\
\hline & z & -1.508 & -2.198 & 1.184 & -.507 & .507 & -1.184 & .169 & .845 \\
\hline & Asymp. Sig. (2-tailed) & .132 & .028 & .237 & .612 & .612 & .237 & .866 & .398 \\
\hline$\overline{\mathrm{NO} .08-}$ & Test Value $^{a}$ & 15.0000000 & 38.5050000 & .0342105 & 71.3000000 & 73.9000000 & 70.1500000 & 65.1500000 & 8.7000000 \\
\hline BS1 & Cases $<$ Test Value & 19 & 19 & 19 & 19 & 18 & 19 & 19 & 18 \\
\hline & Cases $>=$ Test Value & 19 & 19 & 19 & 19 & 20 & 19 & 19 & 20 \\
\hline & Total Cases & 38 & 38 & 38 & 38 & 38 & 38 & 38 & 38 \\
\hline & Number of Runs & 9 & 25 & 17 & 19 & 19 & 15 & 21 & 18 \\
\hline & z & -3.454 & 1.480 & -.822 & -.164 & -.148 & -1.480 & .164 & -.477 \\
\hline & Asymp. Sig. (2-tailed) & .001 & .139 & .411 & .869 & .883 & .139 & .869 & .633 \\
\hline NO.09- & Test Value $^{a}$ & 6.0000000 & 23.6400000 & $.0000000^{b}$ & 68.8000000 & 71.8000000 & 68.0000000 & 62.8000000 & 9.6000000 \\
\hline WS1 & Cases $<$ Test Value & 20 & 22 & 0 & 21 & 22 & 22 & 22 & 22 \\
\hline & Cases $>=$ Test Value & 25 & 23 & 45 & 24 & 23 & 23 & 23 & 23 \\
\hline & Total Cases & 45 & 45 & 45 & 45 & 45 & 45 & 45 & 45 \\
\hline & Number of Runs & 19 & 14 & $1^{c}$ & 16 & 16 & 18 & 18 & 23 \\
\hline & z & -1.137 & -2.712 & & -2.090 & -2.109 & -1.505 & -1.505 & .000 \\
\hline & Asymp. Sig. (2-tailed) & .256 & .007 & & .037 & .035 & .132 & .132 & 1.000 \\
\hline$\overline{\mathrm{NO} .10-}$ & Test Value $^{\mathrm{a}}$ & 61.0000000 & 37.8900000 & .0900000 & 74.8000000 & 76.8000000 & 73.0000000 & 69.6000000 & 7.6000000 \\
\hline FF2 & Cases $<$ Test Value & 15 & 11 & 13 & 15 & 15 & 14 & 14 & 15 \\
\hline & Cases $>=$ Test Value & 16 & 20 & 18 & 16 & 16 & 17 & 17 & 16 \\
\hline & Total Cases & 31 & 31 & 31 & 31 & 31 & 31 & 31 & 31 \\
\hline & Number of Runs & 6 & 13 & 18 & 13 & 15 & 11 & 7 & 16 \\
\hline & z & -3.652 & -.678 & .527 & -1.091 & -.360 & -1.791 & -3.267 & .000 \\
\hline & Asymp. Sig. (2-tailed) & .000 & .498 & .598 & .275 & .719 & .073 & .001 & 1.000 \\
\hline
\end{tabular}


Xiaodong Lu, Jian Kang, Peisheng Zhu, Jun Cai, Fei Guo, Yuan Zhang: Transportation Research Part D https://doi.org/10.1016/j.trd.2019.08.026

\begin{tabular}{|c|c|c|c|c|c|c|c|c|c|}
\hline \multicolumn{2}{|c|}{ Road Name } & \multirow{2}{*}{$\begin{array}{l}\text { NVG } \\
128.0000000\end{array}$} & \multirow{2}{*}{$\begin{array}{l}\text { Speed } \\
39.9500000\end{array}$} & \multirow{2}{*}{$\begin{array}{l}\text { HVP } \\
.0600000\end{array}$} & \multirow{2}{*}{$\begin{array}{l}\text { LAeq } \\
77.0000000\end{array}$} & \multirow{2}{*}{$\begin{array}{l}\text { L10 } \\
78.9000000\end{array}$} & \multirow{2}{*}{$\begin{array}{l}\text { L50 } \\
76.2000000\end{array}$} & \multirow{2}{*}{$\begin{array}{l}\text { L90 } \\
73.2000000\end{array}$} & \multirow{2}{*}{$\begin{array}{l}\text { L10-L90 } \\
5.9000000\end{array}$} \\
\hline$\overline{\mathrm{NO} .11-}$ & Test Value $^{\mathrm{a}}$ & & & & & & & & \\
\hline GRJ2 & Cases $<$ Test Value & 14 & 14 & 12 & 13 & 14 & 14 & 14 & 14 \\
\hline & Cases $>=$ Test Value & 15 & 15 & 17 & 16 & 15 & 15 & 15 & 15 \\
\hline & Total Cases & 29 & 29 & 29 & 29 & 29 & 29 & 29 & 29 \\
\hline & Number of Runs & 13 & 14 & 15 & 8 & 14 & 12 & 12 & 11 \\
\hline & z & -.751 & -.372 & .000 & -2.618 & -.372 & -1.129 & -1.129 & -1.508 \\
\hline & Asymp. Sig. (2-tailed) & .453 & .710 & 1.000 & .009 & .710 & .259 & .259 & .132 \\
\hline$\overline{\mathrm{NO}} .12-$ & Test Value $^{\mathrm{a}}$ & 18.0000000 & 30.4200000 & $.0000000^{6}$ & 72.8000000 & 74.9000000 & 71.3000000 & 67.2000000 & 7.9500000 \\
\hline WS2 & Cases $<$ Test Value & 21 & 19 & 0 & 21 & 22 & 21 & 20 & 22 \\
\hline & Cases $>=$ Test Value & 23 & 25 & 44 & 23 & 22 & 23 & 24 & 22 \\
\hline & Total Cases & 44 & 44 & 44 & 44 & 44 & 44 & 44 & 44 \\
\hline & Number of Runs & 9 & 23 & $1^{\mathrm{c}}$ & 22 & 22 & 18 & 25 & 19 \\
\hline & z & -4.113 & .000 & & -.139 & -.153 & -1.362 & .517 & -1.068 \\
\hline & Asymp. Sig. (2-tailed) & .000 & 1.000 & & .889 & .879 & .173 & .605 & .286 \\
\hline NO.13- & Test Value $^{\mathrm{a}}$ & 3.0000000 & 25.3900000 & $.0000000^{6}$ & 67.9000000 & 71.4000000 & 65.9000000 & 59.3000000 & 12.1000000 \\
\hline MZ & Cases $<$ Test Value & 17 & 21 & 0 & 22 & 21 & 22 & 22 & 22 \\
\hline & Cases $>=$ Test Value & 28 & 24 & 45 & 23 & 24 & 23 & 23 & 23 \\
\hline & Total Cases & 45 & 45 & 45 & 45 & 45 & 45 & 45 & 45 \\
\hline & Number of Runs & 14 & 22 & $1^{\mathrm{c}}$ & 27 & 22 & 29 & 29 & 18 \\
\hline & z & -2.459 & -.273 & & .909 & -.273 & 1.512 & 1.512 & -1.505 \\
\hline & Asymp. Sig. (2-tailed) & .014 & .785 & & .364 & .785 & .131 & .131 & .132 \\
\hline NO.14- & Test Value $^{\mathrm{a}}$ & 3.0000000 & 28.8000000 & $.0000000^{b}$ & 65.6000000 & 69.4000000 & 62.8000000 & 58.0000000 & 11.3000000 \\
\hline YP & Cases $<$ Test Value & 10 & 11 & 0 & 10 & 11 & 11 & 11 & 11 \\
\hline & Cases $>=$ Test Value & 13 & 12 & 23 & 13 & 12 & 12 & 12 & 12 \\
\hline & Total Cases & 23 & 23 & 23 & 23 & 23 & 23 & 23 & 23 \\
\hline & Number of Runs & 16 & 12 & $1^{\mathrm{c}}$ & 12 & 13 & 12 & 10 & 16 \\
\hline & z & 1.389 & .000 & & .000 & .009 & .000 & -.846 & 1.292 \\
\hline & Asymp. Sig. (2-tailed) & .165 & 1.000 & & 1.000 & .993 & 1.000 & .398 & .196 \\
\hline NO.15- & Test Value $^{6}$ & 4.0000000 & 15.1700000 & $.0000000^{b}$ & 67.5500000 & 71.5500000 & 65.1000000 & 57.5500000 & 13.7500000 \\
\hline SC & Cases $<$ Test Value & 15 & 21 & 0 & 21 & 21 & 21 & 21 & 21 \\
\hline & Cases $>=$ Test Value & 27 & 21 & 42 & 21 & 21 & 21 & 21 & 21 \\
\hline & Total Cases & 42 & 42 & 42 & 42 & 42 & 42 & 42 & 42 \\
\hline & Number of Runs & 13 & 15 & $1^{\mathrm{c}}$ & 19 & 23 & 20 & 23 & 19 \\
\hline & z & -2.314 & -2.031 & & -.781 & .156 & -.469 & .156 & -.781 \\
\hline & Asymp. Sig. (2-tailed) & .021 & .042 & & .435 & .876 & .639 & .876 & .435 \\
\hline$\overline{\mathrm{NO}}$.16- & Test Value $^{a}$ & 4.5000000 & 36.5500000 & $.0000000^{b}$ & 70.6500000 & 73.7500000 & 68.6500000 & 63.0000000 & 10.2500000 \\
\hline $\mathrm{YH}$ & Cases $<$ Test Value & 20 & 19 & 0 & 20 & 20 & 20 & 20 & 20 \\
\hline & Cases $>=$ Test Value & 20 & 21 & 40 & 20 & 20 & 20 & 20 & 20 \\
\hline & Total Cases & 40 & 40 & 40 & 40 & 40 & 40 & 40 & 40 \\
\hline & Number of Runs & 16 & 22 & $1^{\mathrm{c}}$ & 16 & 18 & 16 & 15 & 27 \\
\hline & z & -1.442 & .177 & & -1.442 & -.801 & -1.442 & -1.762 & 1.762 \\
\hline & Asymp. Sig. (2-tailed) & .149 & .860 & & .149 & .423 & .149 & .078 & .078 \\
\hline NO.17- & Test Value $^{a}$ & 8.5000000 & 45.1700000 & $.0000000^{b}$ & 72.7000000 & 75.8000000 & 71.1000000 & 66.3000000 & 9.9500000 \\
\hline NS1 & Cases $<$ Test Value & 21 & 20 & 0 & 20 & 19 & 19 & 20 & 21 \\
\hline & Cases $>=$ Test Value & 21 & 22 & 42 & 22 & 23 & 23 & 22 & 21 \\
\hline & Total Cases & 42 & 42 & 42 & 42 & 42 & 42 & 42 & 42 \\
\hline & Number of Runs & 15 & 20 & $1^{\mathrm{c}}$ & 21 & 19 & 24 & 20 & 20 \\
\hline & z & -2.031 & -.455 & & -.142 & -.728 & .533 & -.455 & -.469 \\
\hline & Asymp. Sig. (2-tailed) & .042 & .649 & & .887 & .466 & .594 & .649 & .639 \\
\hline NO.18- & Test Value $^{\mathrm{a}}$ & 6.5000000 & 39.6950000 & $.0000000^{b}$ & 71.5500000 & 74.4500000 & 70.0000000 & 65.6000000 & 9.0500000 \\
\hline NS2 & Cases $<$ Test Value & 13 & 13 & 0 & 13 & 13 & 12 & 13 & 13 \\
\hline & Cases $>=$ Test Value & 13 & 13 & 26 & 13 & 13 & 14 & 13 & 13 \\
\hline & Total Cases & 26 & 26 & 26 & 26 & 26 & 26 & 26 & 26 \\
\hline & Number of Runs & 6 & 10 & $1^{\mathrm{c}}$ & 10 & 10 & 11 & 10 & 14 \\
\hline & z & -3.002 & -1.401 & & -1.401 & -1.401 & -.976 & -1.401 & .000 \\
\hline & Asymp. Sig. (2-tailed) & .003 & .161 & & .161 & .161 & .329 & .161 & 1.000 \\
\hline NO.19- & Test Value $^{\mathrm{a}}$ & 13.0000000 & 40.5600000 & .0400000 & 73.0000000 & 75.9000000 & 71.3000000 & 64.0000000 & 11.6000000 \\
\hline NS3 & Cases $<$ Test Value & 18 & 19 & 19 & 20 & 20 & 18 & 19 & 20 \\
\hline & Cases $>=$ Test Value & 23 & 22 & 22 & 21 & 21 & 23 & 22 & 21 \\
\hline & Total Cases & 41 & 41 & 41 & 41 & 41 & 41 & 41 & 41 \\
\hline & Number of Runs & 14 & 14 & 22 & 19 & 19 & 18 & 20 & 20 \\
\hline & z & -2.151 & -2.192 & .035 & -.629 & -.629 & -.866 & -.283 & -.313 \\
\hline & Asymp. Sig. (2-tailed) & .032 & .028 & .972 & .529 & .529 & .387 & .777 & .755 \\
\hline N0.20- & Test Value $^{\mathrm{a}}$ & 5.0000000 & 46.9500000 & $.0000000^{6}$ & 74.0500000 & 76.8000000 & 72.6000000 & 69.1000000 & 7.0000000 \\
\hline$Q Q$ & Cases $<$ Test Value & 17 & 21 & 0 & 21 & 20 & 20 & 20 & 19 \\
\hline & Cases $>=$ Test Value & 25 & 21 & 42 & 21 & 22 & 22 & 22 & 23 \\
\hline & Total Cases & 42 & 42 & 42 & 42 & 42 & 42 & 42 & 42 \\
\hline & Number of Runs & 20 & 23 & $1^{\mathrm{c}}$ & 23 & 19 & 20 & 22 & 20 \\
\hline & $\mathrm{z}$ & -.240 & .156 & & .156 & -.768 & -.455 & .000 & -.413 \\
\hline & Asymp. Sig. (2-tailed) & .811 & .876 & & .876 & .442 & .649 & 1.000 & .680 \\
\hline
\end{tabular}

b. All values are greater than or less than the cut-off. Runs test cannot be performed.

c. Only one run occurs. Runs test cannot be performed. 
Table A.2. Goodness-of-fit measures for SEM of other indicators of noise intensity $(N=742)$

\begin{tabular}{|c|c|c|c|c|c|c|c|c|}
\hline \multicolumn{2}{|c|}{ Fit indices } & $x^{2} / d f$ & RMSEA & $\mathrm{CFI}$ & $\mathrm{IFI}$ & $\mathrm{TLI}$ & GFI & AGFI \\
\hline \multicolumn{2}{|c|}{ Recommended value } & $<2.00$ & $<0.05$ & $>0.90$ & $>0.90$ & $>0.90$ & $>0.90$ & $>0.90$ \\
\hline \multirow[t]{3}{*}{ Model } & $E$ & 1.698 & 0.031 & 0.999 & 0.999 & 0.990 & 0.999 & 0.982 \\
\hline & $\mathrm{F}$ & 1.698 & 0.031 & 0.999 & 0.999 & 0.991 & 0.999 & 0.982 \\
\hline & G & 1.698 & 0.031 & 0.999 & 0.999 & 0.990 & 0.999 & 0.982 \\
\hline
\end{tabular}

Note. Model E: Structural equation model with L10 as the dependent variable; Model F: Structural equation model with L50 as the dependent variable; Model G: Structural equation model with L90 as the dependent variable.

Note. $\mathrm{X}^{2} / \mathrm{df}$ : chi square to df ratio; RMSEA: root-mean-square error of approximation; $\mathrm{CFI}$ : comparative fit index; IFI: incremental fit index; TLI: Tucker-Lewis index; GFI: goodness-of-fit index; AGFI, adjusted goodness-of-fit.

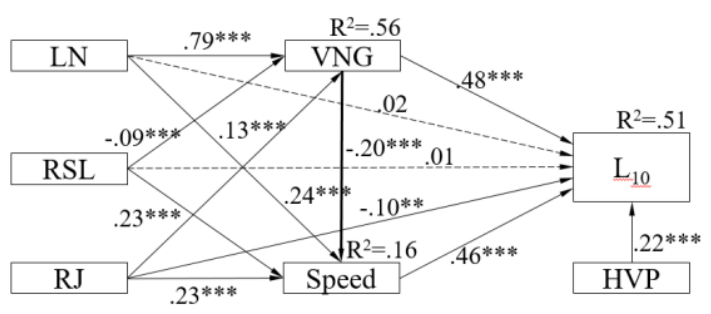

a) Model E

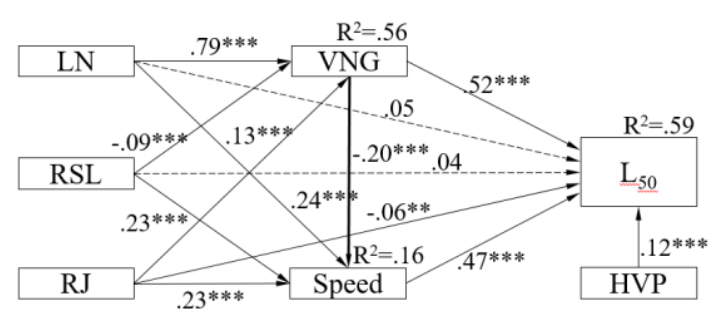

b) Model F

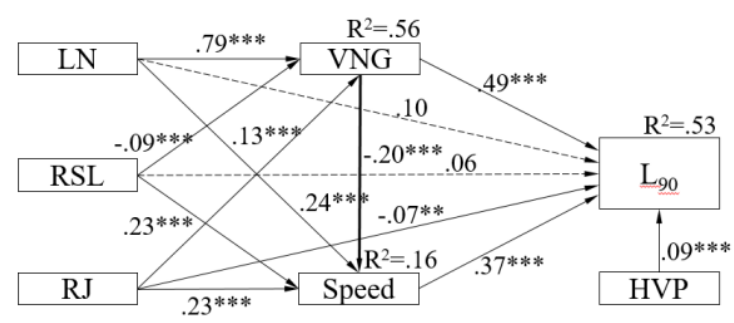

c) Model G

Fig. A.1. Structural equation models for other indicators of noise intensity

(a) Model E: Structural equation model with $L_{10}$ as the dependent variable; (b) Model F: Structural equation model with $L_{50}$ as the dependent variable; (c) Model G: Structural equation model with $L_{90}$ as the dependent variable.

Note. $\mathrm{x}^{2} / \mathrm{df}$ : chi square to $\mathrm{df}$ ratio; RMSEA: root-mean-square error of approximation; CFI: comparative fit index; IFI: incremental fit index; TLI: Tucker-Lewis index; GFI: goodness-of-fit index; AGFI, adjusted goodness-of-fit. 